\title{
EFFECT OF ALIGNED MAGNETIC FIELD AND INCLINED OUTER VELOCITY IN CASSON FLUID FLOW OVER A STRETCHING SHEET WITH HEAT SOURCE
}

\author{
Renu Devi ${ }^{1}$, Vikas Poply² ${ }^{\star}$, Manimala $^{1}$
}

\begin{abstract}
The purpose of this study was to assess the effect of the inclined outer velocity on heat and flow transportation in boundary layer Casson fluid over a stretching sheet. The flow is adopted to have non-orthogonal magnetic field with heat generation in the uniform manner on stretching surface. It has been taken that in both the directions along the $\mathrm{x}$ axis, the sheet is stretched. By applying similarity transformations, the governing equations representing the heat and flow transportation are converted to ordinary differential equations. Runge-Kutta Fehlberg approach was adopted to solve numerically the moulded differential equations with the help of shooting technique. The flow is also governed by the heat source parameter, Casson fluid parameter, magnetic parameter, Prandtl number, aligned angle of magnetic field and the impinging angle parameter. The results revealed that velocity decreases with an increase in Casson fluid parameter, magnetic parameter and aligned angle of magnetic field for the case of outer velocity parameter less than one while velocity increases for the case of outer velocity parameter greater than one because of the inverted boundary layer formation for velocity profile in second case. Also, the fluid temperature increases (for the case of outer velocity parameter less than one) and temperature decreases (for the case of outer velocity parameter greater than one) with an increase in Casson fluid parameter, impinging angle parameter and aligned angle parameter. The results indicate that outer velocity and aligned magnetic field has a significant impact on fluid temperature and velocity. The behaviour of emerging fluid parameters on fluid temperature and velocity are depicted graphically and their effect on local Nusselt number $\left(N u_{x}\right)$ and skin friction coefficient $\left(C_{f}\right)$ are represented by tables. The finding of this study may serve as to control the rate of heat transportation and fluid velocity in many manufacturing processes and industrial applications to make the desired quality of final product. Acceptance of the extant technique used in current study is correlated with the existing outcomes in the literature.
\end{abstract}

Keywords: Casson fluid, Aligned magnetic field, Outer velocity, Oblique flow, Heat source.

\section{INTRODUCTION}

Numerous practical importance of flow and heat transfer over a stretching surface in several divisions of manufacturing procedures lead attention of many researchers in such field like aerodynamic shaping of plastic sheet, cooling of metallic or glass plates, polymer processing, condensation processing, manufacturing and stretching of plastic films, extrusion of metal and polymer sheet, artificial fibers, wire drawing etc. Apart from these, the applications regarding the rate of heat transfer in fluid occurs in technological processes like solar energy, petroleum refining and nuclear reactors etc. In industries, metal and polymer involve the drawing of strip which becomes stretched sometime. In such processes, the desired quality of product has not obtained due to uncontrolled rate of heat transfer on the stretched surface. To overcome this difficulty, the outer velocity flow and magneto hydrodynamic (MHD) flow plays a significant role in controlling the heat transfer rate on stretching surfaces and improving the quality of final product.

Crane [1] initiated the work on stretching surfaces by analyzing the heat and flow characteristics over stretching sheet and examined on boundary layer flow behavior over stretched sheet which is useful in many real-life applications like printer ink, condensed milk, glue, sugar, paint and paste etc. Many researchers [2-4] further extended this study by analyzing the impact on flow characteristics in various situations and different surfaces, where theoretical results are covenant with experimental results. Although, in some real-world application like extrusion of sheet, aerodynamic shaping etc. fluid has some prescribed velocity. Many researchers analyzed the effect of the outer velocity and stagnation-point flow over stretching surfaces [5-12]. Mukhopadhyay and Layek [13] study the impact of variable

This paper was recommended for publication in revised form by Regional Editor Mehdi Bahiraei

${ }^{1}$ Department of Mathematics, Ansal University, Gurgaon-122017, India

${ }^{2}$ Department of Mathematics, KLP College, Rewari-123401, India

${ }^{*}$ E-mail address: vikaspoply@gmail.com

Orcid Id: 0000-0002-6510-1967, 0000-0002-1573-3210, 0000-0002-7645-3183

Manuscript Received 17 April 2019, Accepted 18 September 2019 
viscosity on stretching sheet in presence of heat source/sink and reported that the thermal boundary layer increases in the presence of internal heat source.

Study of magnetic field play a vital role in industrial and manufacturing processes, such as in cooling of reactors, metallurgical process, power generator and also helpful in earthquake assumption.MHD used in medicine i.e., tumour or cancer treatment. It is also used in plasma, salt water and liquid metal which roll as electrically conducting fluid. Several applications of MHD flows locate in liquid metal flow control, high temperature plasma and micro MHD pump etc. Effect of porosity on MHD flow over stretching sheet in presence of heat source has been discussed by $[14,15]$ and explained the temperature distribution rate increases with increasing heat source parameter. Many biological as well as industrial driven fluids such as multi-tude oils, lubricating greases, gypsum pastes, cleansing agents, blood, ceramics, paints etc., the flow behavior does not pertain as Newtonian fluid. Therefore, numerous works have been done for non-Newtonian fluids, like viscoelastic fluid, power-law fluid and Casson fluid due to its vast applications in petroleum drilling polymer engineering and paper production etc. In particular, Casson fluid model explained as shear thinning liquid with infinite viscosity at zero shear rate and a zero viscosity at an infinite rate of shear. The Casson fluid model containing several food stuffs and biological materials, especially blood. Casson fluid is used properly the flow curves of suspensions of pigments in lithographic varnishes utilized for preparing in printer ink, silicon suspension as well as its industrial applications are such as design of thrust bearings and radial diffusers, transpiration cooling, thermal oil recovery and drag reduction etc. Ahmed et al. [16] discuss the effect of Casson fluid on stretching sheet and reported that with increasing Casson fluid parameter, fluid velocity decreases. Mustafa et al. [17] investigated the boundary layer flow of Casson fluid near the stagnation point on stretching surface and his current results limited for Casson fluid parameter up to infinity by using Homotopy pertubation method (HPM). Dual solution on Casson fluid over stretching sheet has been reported by Kameswaran et al. [18] and Bhattacharya et al. [19]. Effect of slip velocity on unsteady stretching sheet due to Casson fluid with variable heat flux has been examined by Megahed [20] and stated that increasing values of the Casson fluid parameter causes a decline in both the film thickness and the skin-friction coefficient. Some researchers [21-24] studied the effect of magnetic field over stretching surface in presence of Casson fluid under different physical conditions. Prabhakar et al. [25] examined the effect of inclined magnetic field, thermal slip and velocity slip of Casson nanofluid over an exponentially stretched sheet and they reported that the magnetic field reduces the momentum boundary thickness. Influence of heat generation on Casson fluid over stretching/shrinking sheet investigated by [26, 27] and both reported that fluid temperature increases with the increase in heat generation. The two-dimensional steady flow of an incompressible viscous fluid impinging on a stretching sheet obliquely is discussed in [28-31]. Lok et al. [32, 33] studied the impact of oblique flow in a micropolar and non-micro-polar fluid over a stretching surface.

Most of the MHD studies over stretching surfaces are centered on the enforcement of the normal magnetic field. However, in some manufacturing process due to some geometrical constraints magnetic field cannot be applied normal to the surfaces. Therefore, it is essential to study the influence of aligned magnetic field over stretching surfaces. Impact of MHD nanofluid with existence of porous medium is revealed by [34-37] Sulochana et al. [38] discussed impact of inclined magnetic field on nanofluid over an exponentially permeable stretched sheet. Effect of outer velocity flow on heat and flow characteristics studied in [39, 40].

The above literature survey reveals that no study had discussed so far to analyze the impact of aligned magnetic field on oblique stagnation point flow with inclined outer velocity over a stretching surface with volumetric rate of heat generation/absorption. The aim of this study is to examine the combined effect of inclined outer velocity and aligned magnetic field over a stretching sheet with internal heat source in a Casson fluid. The results revealed that velocity decreases with an increase in Casson fluid parameter, magnetic parameter and aligned angle of magnetic field for the case of outer velocity parameter less than one while velocity increases for the case of outer velocity parameter greater than one because of the inverted boundary layer formation for velocity profile. Also, the fluid temperature increases (for the case of outer velocity parameter less than one) and temperature decreases (for the case of outer velocity parameter greater than one) with an increase in Casson fluid parameter, impinging angle parameter and aligned angle parameter. The results indicate that outer velocity has a significant impact on fluid temperature and velocity. The finding of this study may serve as to control the rate of heat transportation and fluid velocity in many manufacturing processes and industrial applications to make the desire quality of the final product. 


\section{MATERIALS AND METHODS}

Steady 2D Casson fluid flow of a non-compressible, viscous, non-orthogonally electrical conducting fluid on a stretching sheet with orthogonal and inclined outer velocity flow is considered (showed by Figure 1 and Figure 2 respectively). Heat generation and aligned magnetic field are also assumed to impact the fluid flow. $u_{w}(x)$ and $T_{w}(x)$ are the linear velocity and uniform temperature on stretching surface respectively. The induced magnetic field is neglected because of very small intensity as compared to the applied magnetic field. Also, the viscous dissipation and joule heating effects are neglected.

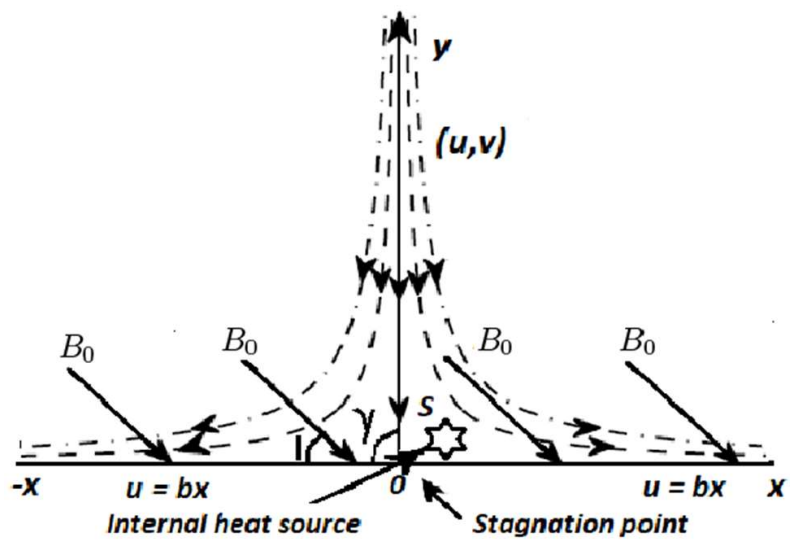

Figure 1. Schematic diagram for orthogonal flow

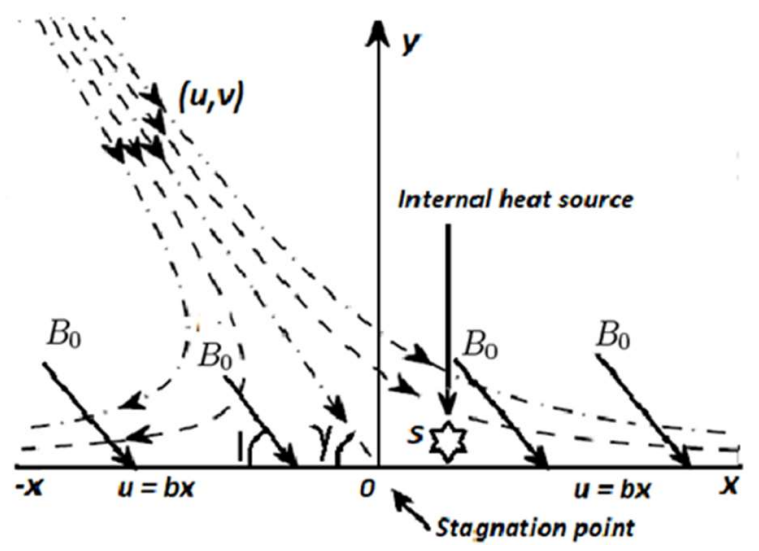

Figure 2. Schematic diagram for oblique flow

The generating equations of flow under the above assumptions are described as:

$$
\begin{gathered}
\frac{\partial u}{\partial x}+\frac{\partial v}{\partial y}=0 \\
u \frac{\partial u}{\partial x}+v \frac{\partial u}{\partial y}=-\frac{1}{\rho} \frac{\partial P}{\partial x}+v\left(1+\frac{1}{\beta}\right)\left(\frac{\partial^{2} u}{\partial x^{2}}+\frac{\partial^{2} u}{\partial y^{2}}\right)-\frac{\sigma B_{0}^{2} u \sin ^{2} l}{\rho} \\
u \frac{\partial v}{\partial x}+v \frac{\partial v}{\partial y}=-\frac{1}{\rho} \frac{\partial P}{\partial y}+v\left(1+\frac{1}{\beta}\right)\left(\frac{\partial^{2} v}{\partial x^{2}}+\frac{\partial^{2} v}{\partial y^{2}}\right)
\end{gathered}
$$




$$
u \frac{\partial T}{\partial x}+v \frac{\partial T}{\partial y}=\frac{K}{\rho C_{P}} \frac{\partial^{2} T}{\partial y^{2}}+\frac{Q}{\rho C_{P}}\left(T-T_{\infty}\right)
$$

Where velocity along y (vertical axis) and $\mathrm{x}$ (horizontal axis) - axes are taken as $\mathrm{v}$ and $\mathrm{u}$ respectively. $P, v, \sigma, \mathrm{l}, \rho, \mathrm{C}_{\mathrm{P}}, \mathrm{T}, \mathrm{Q}, \mathrm{K}, \beta$ and $B_{0}$ denotes the pressure, kinematic viscosity, electrical conductivity, angle of magnetic field, density, specific heat at constant pressure, temperature of fluid, heat generation, thermal conductivity, Casson fluid parameter and magnetic field strength of the fluid respectively.

Restrictions on the boundary are describing the flow model as:

$$
\left(\begin{array}{cr}
y=0 & u=u_{w}(x)=b x, \quad v=0, T=T_{w} \\
y \rightarrow \infty & u=n x \sin \gamma+m y \cos \gamma, v=-n y \sin \gamma, T=T_{\infty}
\end{array}\right)
$$

Where $\mathrm{b}, \mathrm{n}$ and $\mathrm{m}$ are non-negative invariable values of dimension $\left(\right.$ time $\left.^{-1}\right)$. The fluid having unvarying temperature $T_{\infty}$ very far from the surface and $\gamma$ is impinging angle from the $\mathrm{x}$-axis, at which Casson fluid striking the stretching sheet (striking angle parameter). Differentiate partially equations (2) and (3) w.r.t. y and x respectively and eliminating the term containing $\mathrm{P}$, we obtained

$$
\begin{aligned}
\frac{\partial u}{\partial y} \frac{\partial u}{\partial x}+ & u \frac{\partial^{2} u}{\partial x \partial y}+\frac{\partial v}{\partial y} \frac{\partial u}{\partial y}+v \frac{\partial^{2} u}{\partial y^{2}}-\frac{\partial u}{\partial x} \frac{\partial v}{\partial x}-u \frac{\partial^{2} v}{\partial x^{2}}-\frac{\partial v}{\partial x} \frac{\partial v}{\partial y}-v \frac{\partial^{2} v}{\partial x \partial y} \\
& =v\left(1+\frac{1}{\beta}\right)\left(\frac{\partial^{3} u}{\partial y \partial x^{2}}+\frac{\partial^{3} u}{\partial y^{3}}-\frac{\partial^{3} v}{\partial x^{3}}-\frac{\partial^{3} v}{\partial x \partial y^{2}}\right)-\frac{\sigma B_{0}^{2} \sin ^{2} l}{\rho} \frac{\partial u}{\partial y}
\end{aligned}
$$

Introducing similarity variables $\xi=\sqrt{\frac{b}{v}} \mathrm{x}, \eta=\sqrt{\frac{b}{v}} \mathrm{y}$ and stream function $\psi=\xi f_{0}(\eta)+g_{0}(\eta)[6,29]$ such that $u=\frac{\partial \psi}{\partial \eta}$ and $v=-\frac{\partial \psi}{\partial \xi}$, where $g_{0}(\eta)$ and $f_{0}(\eta)$ are referred as tangential and normal part of the flow. Also, $v=$ $-f_{0}(\eta)$ andu $=\xi f_{0}{ }^{\prime}(\eta)+g_{0}{ }^{\prime}(\eta)$. The Boundary conditions in term of stream function $\psi(\xi, \eta)$ is given by,

$$
\left(\begin{array}{cc}
\psi=0, \quad \frac{\partial \psi}{\partial \eta}=\xi & \text { on } \eta=0 \\
\psi=\lambda \xi \eta \sin \gamma+\frac{1}{2} R \eta^{2} \cos \gamma & \text { as } \eta \rightarrow \infty
\end{array}\right)
$$

Where $\lambda=\frac{n}{b}$ is outer velocity parameter and $R=\frac{m}{b}$ is some positive constant.

Furthermore, equation (1) is contented by given $\mathrm{v}$ and $\mathrm{u}$ and equation (6) transformed to,

$$
\begin{aligned}
f_{0}{ }^{\prime}(\eta)\left[\xi f_{0}{ }^{\prime \prime}(\eta)\right. & \left.+g_{0}{ }^{\prime \prime}(\eta)\right]+\left[\xi f_{0}{ }^{\prime}(\eta)+g_{0}{ }^{\prime}(\eta)\right] f_{0}{ }^{\prime \prime}(\eta)-f_{0}{ }^{\prime}(\eta)\left[\xi f_{0}{ }^{\prime \prime}(\eta)+g_{0}{ }^{\prime \prime}(\eta)\right] \\
& -f_{0}(\eta)\left[\xi f_{0}{ }^{\prime \prime \prime}(\eta)+g_{0}{ }^{\prime \prime \prime}(\eta)\right] \\
& =\left(1+\frac{1}{\beta}\right)\left[\xi f_{0}{ }^{\prime \prime \prime \prime}(\eta)+g_{0}{ }^{\prime \prime \prime \prime}(\eta)\right]-M \sin ^{2} l\left[\xi f_{0}{ }^{\prime \prime}(\eta)+g_{0}{ }^{\prime \prime}(\eta)\right]
\end{aligned}
$$

Here $M=\frac{\sigma B_{0}^{2}}{b \rho}$ is the Chandershekhar number (magnetic parameter) [41-43]. Also, comparing the coefficient $\xi$ and $\xi^{0}$ (constant), we get

$$
\left(1+\frac{1}{\beta}\right) f_{0}{ }^{\prime \prime \prime \prime}(\eta)+f_{0}(\eta) f_{0}{ }^{\prime \prime \prime}(\eta)+f_{0}{ }^{\prime}(\eta) f_{0}{ }^{\prime \prime}(\eta)-2{f_{0}}^{\prime}(\eta) f_{0}{ }^{\prime \prime}(\eta)-M \sin ^{2} l f_{0}{ }^{\prime \prime}(\eta)=0
$$


Journal of Thermal Engineering, Research Article, Vol. 7, No. 4, pp. 823-844, May, 2021

$$
\begin{gathered}
\left(1+\frac{1}{\beta}\right) g_{0}{ }^{\prime \prime \prime \prime}(\eta)+f_{0}{ }^{\prime}(\eta) g_{0}{ }^{\prime \prime}(\eta)+f_{0}(\eta) g_{0}{ }^{\prime \prime \prime}(\eta)-f_{0}{ }^{\prime}(\eta) g_{0}{ }^{\prime \prime}(\eta)-g_{0}{ }^{\prime}(\eta) f_{0}{ }^{\prime \prime}(\eta) \\
-M \sin ^{2} l g_{0}{ }^{\prime \prime}(\eta)=0
\end{gathered}
$$

After integrating, equation (9) and (10) w. r. t $\eta$, we get,

$$
\begin{gathered}
\left(1+\frac{1}{\beta}\right) f_{0}{ }^{\prime \prime \prime}(\eta)+f_{0}(\eta) f_{0}^{\prime \prime}(\eta)-\left(f_{0}^{\prime}(\eta)\right)^{2}-M \sin ^{2} l f_{0}{ }^{\prime}(\eta)+C=0 \\
\left(1+\frac{1}{\beta}\right) g_{0}^{\prime \prime \prime}(\eta)+f_{0}(\eta) g_{0}^{\prime \prime}(\eta)-f_{0}^{\prime}(\eta) g_{0}{ }^{\prime}(\eta)-M \sin ^{2} l g_{0}^{\prime}(\eta)+D=0
\end{gathered}
$$

Where $\mathrm{C}$ and $\mathrm{D}$ are constant of integration and determined by the boundary conditions,

$$
\begin{aligned}
& f_{0}(0)=0, f_{0}{ }^{\prime}(0)=1, f_{0}{ }^{\prime}(\infty)=\lambda \sin \gamma \\
& g_{0}(0)=0, g_{0}{ }^{\prime}(0)=0, g_{0}^{\prime \prime}(\infty)=R \cos \gamma
\end{aligned}
$$

Incorporating values of C and D in equations (11) and (12) respectively, we get,

$$
\begin{gathered}
\left(1+\frac{1}{\beta}\right) f_{0}{ }^{\prime \prime \prime}(\eta)+f_{0}(\eta) f_{0}{ }^{\prime \prime}(\eta)-\left(f_{0}{ }^{\prime}(\eta)\right)^{2}-M \sin ^{2} l\left[f_{0}{ }^{\prime}(\eta)-\lambda \sin \gamma\right]+(\lambda \sin \gamma)^{2}=0 \\
\left(1+\frac{1}{\beta}\right) g_{0}{ }^{\prime \prime \prime}(\eta)+f_{0}(\eta) g_{0}{ }^{\prime \prime}(\eta)-f_{0}{ }^{\prime}(\eta) g_{0}{ }^{\prime}(\eta)-M \sin ^{2} l\left[g_{0}^{\prime}(\eta)-R \eta \cos \gamma\right]-\alpha R \cos \gamma=0
\end{gathered}
$$

Further, we find that the linearity of equation (15) can take the solution of the form,

$$
g_{0}{ }^{\prime}(\eta)=R \cos \gamma h_{0}(\eta)
$$

Where, $h_{0}(\eta)$ is define from the equation,

$$
\begin{gathered}
\left(1+\frac{1}{\beta}\right) h_{0}{ }^{\prime \prime}(\eta)+f_{0}(\eta) h_{0}^{\prime}(\eta)-f_{0}{ }^{\prime}(\eta) h_{0}(\eta)-M \sin ^{2} l\left(h_{0}(\eta)-\eta\right)-\alpha=0 \\
h_{0}(0)=0, \quad h_{0}^{\prime}(\infty)=1
\end{gathered}
$$

By considering the normal component of the flow field, the dimensionless temperature $\theta(\eta)=\frac{\left(T-T_{\infty}\right)}{\left(T_{w}-T_{\infty}\right)}$. Substituting $\theta(\eta)$ in equation (4), we get,

$$
\theta^{\prime \prime}(\eta)+\operatorname{Pr} \theta^{\prime}(\eta) f_{0}(\eta)+\operatorname{Pr} S \theta(\eta)=0
$$

Where $S\left(=\frac{Q}{b \rho C_{\mathrm{P}}}\right)$ is heat source parameter and $\operatorname{Pr}\left(=\frac{\mu \mathrm{C}_{\mathrm{P}}}{K}\right)$ is Prandtl number.

Corresponding boundary conditions of equation (5) reduces to,

$$
\theta(0)=1, \quad \theta(\infty)=0
$$


The skin friction coefficient $C_{f}$ and local Nusselt number $N u_{x}$ are given by $C_{f}=\frac{\tau_{\mathrm{w}}}{\rho\left(\mathrm{u}_{\mathrm{w}}\right)^{2}}$ and $N \mathrm{u}_{\mathrm{x}}=\frac{\mathrm{xq}_{\mathrm{w}}}{\mathrm{K}\left(\mathrm{T}_{\mathrm{w}}-\mathrm{T}_{\infty}\right)}$ respectively.

Where, $\tau_{\mathrm{w}}=\left.\mu\left(1+\frac{1}{\beta}\right)\left(\frac{\partial u}{\partial y}\right)\right|_{y=0}$ and $\mathrm{q}_{\mathrm{w}}=-\left.\left(k \frac{\partial T}{\partial y}\right)\right|_{y=0}$.

Here, $\mathrm{C}_{\mathrm{f}} \propto \mathrm{f}_{0}^{\prime \prime}(0)$ and $\mathrm{Nu}_{x} \propto-\theta^{\prime}(0)$.

\section{RESULTS AND DISCUSSION}

The set of non-linear coupled differential equations (14), (17) and (19) subject to boundary conditions (13), (18) and (20) constitute a two-point boundary value problem. In order to solve these equations numerically, we follow most efficient numerical shooting technique with Runge-Kutta Fehlberg integration scheme. In this method it is more important to choose the appropriate finite values of $\eta \rightarrow \infty$. The solution process is repeated with another large values of $\eta \rightarrow \infty$ until two successive values of $f_{0}^{\prime \prime}(0)$ and $\theta^{\prime}(0)$ same up to the desired significant values. The last values of $\eta \rightarrow \infty$ is chosen as appropriate values of the limit $\eta \rightarrow \infty$ for that particular set of parameters. The ordinary differential equations (14), (17) and (19) were first converted into a set of seven first-order simultaneous equations. To solve this system, we require seven initial conditions but we have only four initial conditions, $f_{0}(0)$ and $f_{0}{ }^{\prime}(0)$ on $f_{0}(\eta), h_{0}(0)$ on $h_{0}(\eta)$ and $\theta(0)$ on $\theta(\eta)$. Still there are three initial conditions $f_{0}^{\prime \prime}(0), h_{0}^{\prime}(0)$ and $\theta^{\prime}(0)$ are required, which are not prescribed. However, the values of $f_{0}{ }^{\prime}(\eta), h_{0}{ }^{\prime}(\eta)$ and $\theta(\eta)$ are known at $\eta \rightarrow \infty$. Shooting technique has been employed to find the unknown initial values utilizing these two ending boundary conditions. After finding the required boundary conditions, the problem has been solved numerically using Runge-Kutta Fehlberg integration scheme (showed by Figure 3).

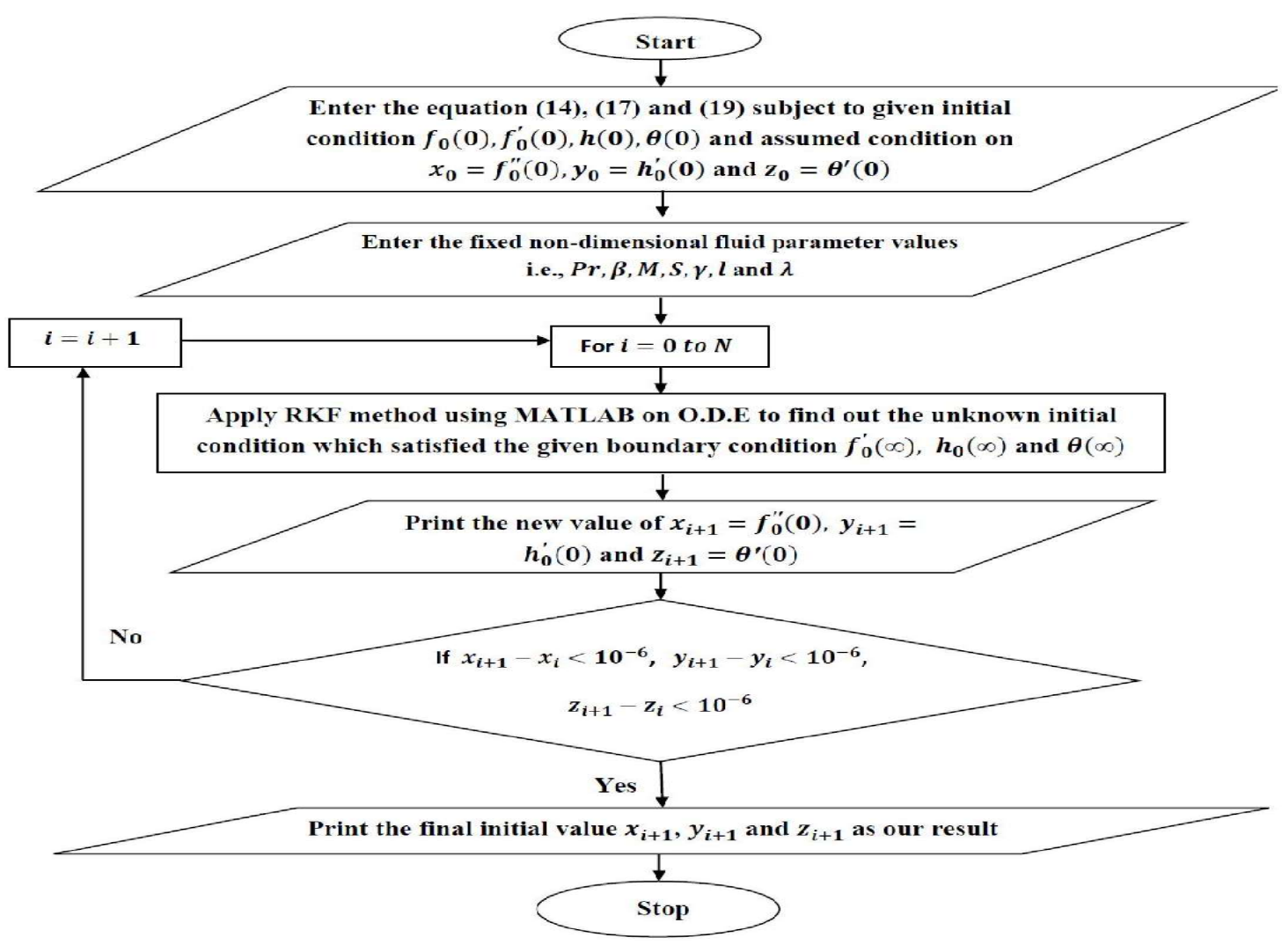

Figure 3. Flow chart for numerical section 
Table 1 and Figure 4 demonstrate the numerical algorithm applied for the current problem is in favourable justification with published work and thus validating the model by numerical algorithm and graphical representation. Velocity and dimensionless temperature of the model have been acquired for different values of outer velocity parameter $\lambda$, Casson fluid parameter $\beta$, strikingangle parameter $\gamma$, magnetic parameter (Chandershekhar number) $\mathrm{M}$ and heat source parameter $\mathrm{S}$. In order to get insights of the fluid behaviour, the value of skin friction coefficients in term of $f_{0}^{\prime \prime}(0)$ and local Nusselt number in term of $-\theta^{\prime}(0)$ have been obtained. Graphs and Tables have been inserted to evaluate the effect of numerous fluid parameters on flow and heat characteristics. The value of horizontal axis - $\eta$ is chosen in such a way that a velocity profiles and temperature profiles asymptotic tends to the boundary condition. All the simulations are carried with $\eta_{\max }=10$ However, to depict the characterization of curve effectively, much lower values of $\eta$ are used.

Table 1. $f_{0}^{\prime \prime}(0)$ for distinct entries of $\lambda$ at large $\beta$ and $l=\pi / 2$, a comparison.

\begin{tabular}{|c|c|c|c|}
\hline$\lambda$ & Present paper & Singh et.al [6] & Lok et.al. [29] \\
\hline 0.1 & -0.969386 & -0.976371 & -0.969388 \\
\hline 0.2 & -0.918107 & -0.921594 & -0.918110 \\
\hline 0.5 & -0.667263 & -0.667686 & -0.667271 \\
\hline 2 & 2.017502 & 2.017476 & 2.017615 \\
\hline
\end{tabular}

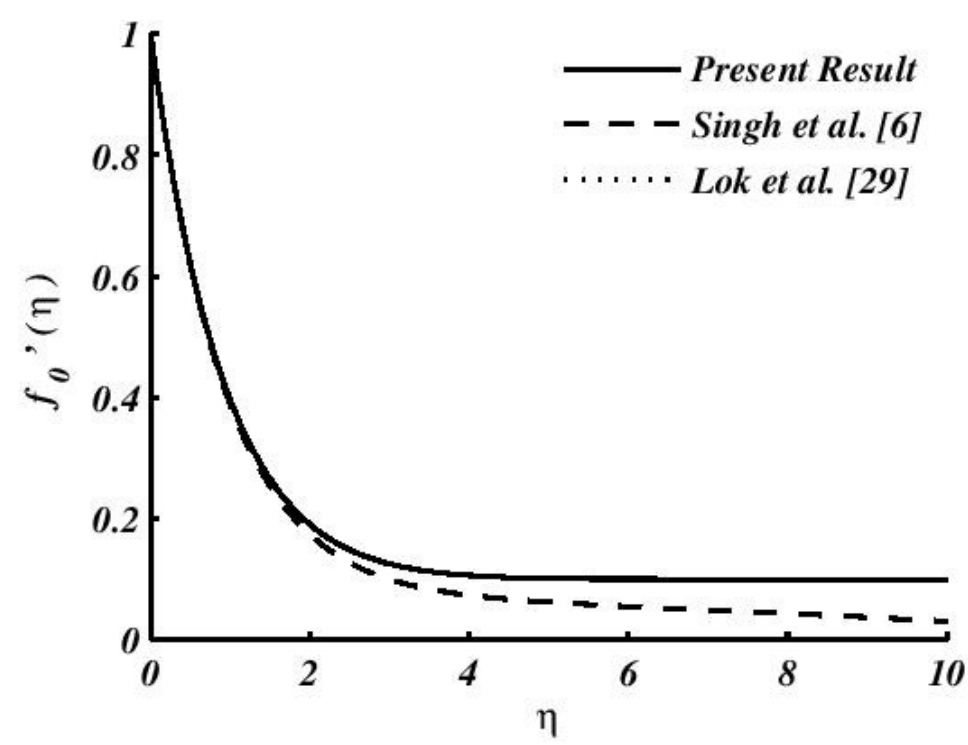

Figure 4. Validation of present work with Singh et al. [6] and Lok et al. [29] for $\lambda=0.1, \gamma=\pi / 2$ and at large $\beta$.

The impact of $\beta$ on profiles of velocity for outer velocity parameter $\lambda=0.5$ and $\lambda=1.5$ as displayed by the Figures 5 and 6 respectively. Physically, $\lambda<1$ explained by the case when stretching sheet velocity exceeds the outer velocity. Figure 5 shows that a reduction in fluid velocity has been observed with the rise in Casson fluid parameter $\beta$ for $\lambda=0.5$. This behaviour is explained by the fact that, increasing the non-Newtonian Casson fluid parameter $\beta$ yields increment in the fluid stress causing a resistance force which makes the fluid velocity decreases. For large value of $\beta$, decrease in boundary layer thickness is noticed for $\lambda=0.5$ (Figure 5). In Figure 6, velocity profile curves increase along with the increase in $\beta$ for $\lambda>1$. An inverted boundary layer is formed in velocity profile in Figure 6 for $\lambda>1$. An opposite trends of velocity profile has been observed for $\lambda=1.5$ in Figure 6 in comparison with $\lambda=0.5$ (shown in Figure 5). 
Journal of Thermal Engineering, Research Article, Vol. 7, No. 4, pp. 823-844, May, 2021

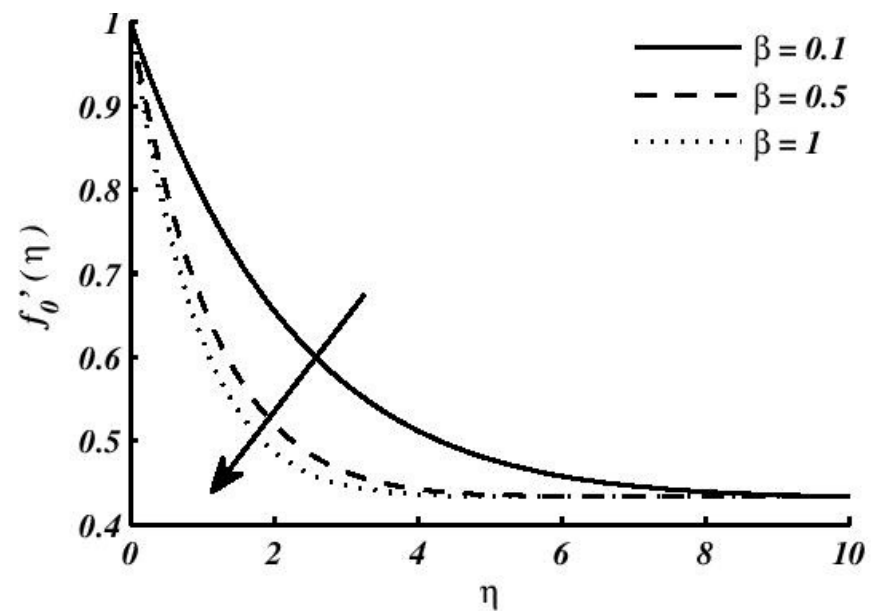

Figure 5. $f_{0}{ }^{\prime}(\eta)$ for distinct $\beta$, when $M=0.5, S=1, l=\pi / 2, R=1, \operatorname{Pr}=0.71, \gamma=\pi / 3$ and $\lambda=0.5$

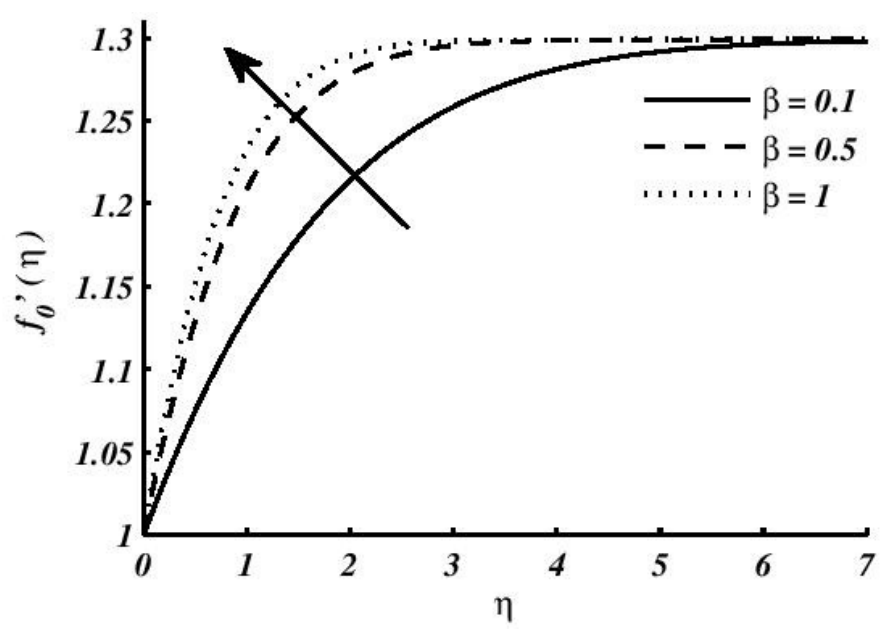

Figure 6. $f_{0}{ }^{\prime}(\eta)$ for distinct $\beta$, when $M=0.5, S=1, l=\pi / 2, R=1, \operatorname{Pr}=0.71, \gamma=\pi / 3$ and $\lambda=1.5$

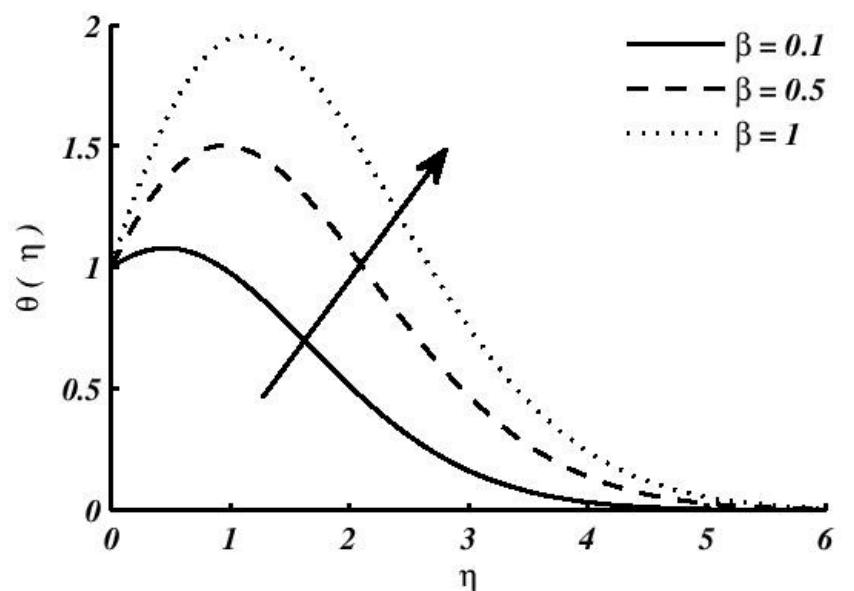

Figure 7. $\theta(\eta)$ for distinct $\beta$, when $M=0.5, S=1, l=\pi / 2, R=1, \operatorname{Pr}=0.71, \gamma=\pi / 3$ and $\lambda=0.5$ 


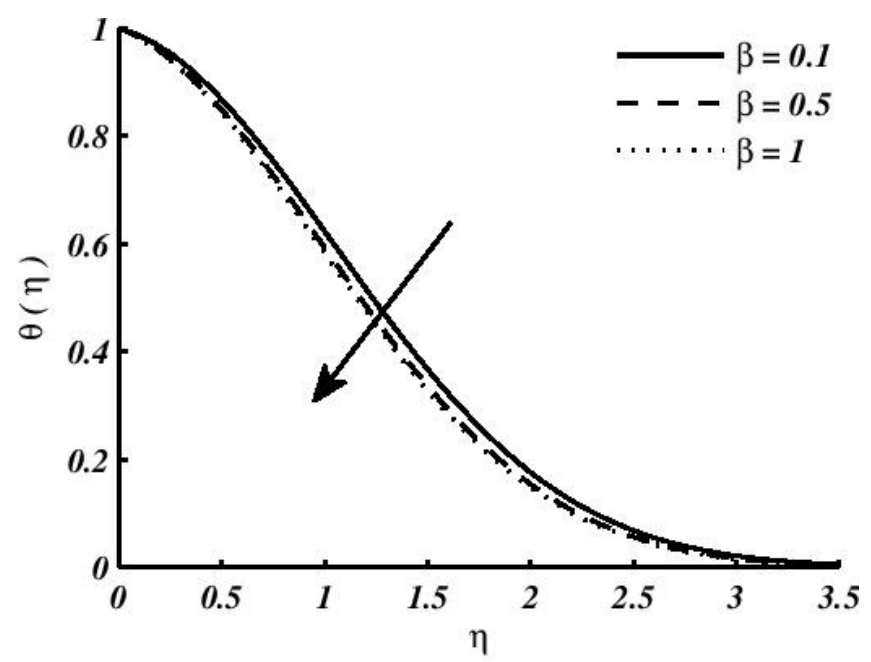

Figure 8. $\theta(\eta)$ for distinct $\beta$, when $M=0.5, S=1, l=\frac{\pi}{2}, R=1, \operatorname{Pr}=0.71, \gamma=\frac{\pi}{3}$ and $\lambda=1.5$

Figures 7 and 8 show the profiles of temperature curves when Casson fluid parameter $\beta=0.1,0.5$ and 1 in presence of $\lambda<1$ and $\lambda>1$ respectively. For a fixed value of $\beta$ in Figure 7, firstly, the temperature curve increases, and it shows a decline in curve after some distance $\eta$. This change in the behaviour of temperature curve is due to the presence of $\beta$. Also, Figure 7 reveals that increase in temperature has been observed with the increase in $\beta$ for $\lambda<1$. As explained in above paragraph that as Casson fluid parameter $\beta$ increases, fluid velocity decrease which results in low heat transfer rate and hence temperature increase for $\lambda=0.5$. Opposite trend in velocity profiles for $\lambda<1$ is the reason for decrease in temperature profiles in the case for $\lambda>1$ (shown in Figure 8). However, the thermal boundary layer thickness is thinner for $\lambda>1$ as compared to that of $\lambda<1$. Table 2 gives computed values proportional to the $C_{f}$ and $N u_{x}$ for distinct magnitude of Casson fluid parameter $\beta$ and outer velocity parameter $\lambda$. We notice from the Table 2 that with the increase in Casson fluid parameter $\beta, C_{f}\left(\propto f_{0}^{\prime \prime}(0)\right)$ and $N u_{x}\left(\propto-\theta^{\prime}(0)\right)$ values decline for $\lambda=$ 0.5 and rise for $\lambda=1.5$.

Table 2. Result of $f_{0}^{\prime \prime}(0)$ and $-\theta^{\prime}(0)$ for different entries of $\beta$, when $M=0.5, S=1, l=\pi / 2, R=1, \operatorname{Pr}=0.71$ and $\gamma=\pi / 3$.

\begin{tabular}{|c|c|c|c|c|}
\hline$\lambda$ & $\alpha$ & $\beta$ & $f_{0}^{\prime \prime}(0)$ & $-\theta^{\prime}(0)$ \\
\hline \multirow{3}{*}{0.5} & 1.14895 & 0.1 & -0.25198 & -0.34955 \\
& 0.60488 & 0.5 & -0.48235 & -1.00275 \\
& 0.49388 & 1 & -0.59076 & -1.55025 \\
\hline \multirow{3}{*}{1.5} & -0.45474 & 0.1 & 0.16858 & 0.10064 \\
& -0.23752 & 0.5 & 0.32280 & 0.14151 \\
& -0.19393 & 1 & 0.39535 & 0.15393 \\
\hline
\end{tabular}

Velocity profiles for distinct entries of $M$ for $\lambda=0.5$ and $\lambda=1.5$ are depicted by the Figures 9 and 10 , respectively. Figure 9 show that reduction in velocity is noticed with an increase in magnetic parameter $M$. Physically this behaviour has been explained as, the magnetic field can induce current on conducting fluid and the transverse magnetic field behaves like a Lorentz force, which produces retardation on fluid boundary layer and the fluid velocity slow down due to the retardation. Consequently, momentum thickness reduces. Hence, fluid magnetism is used to control the desired formation of final object. Figure 10 demonstrates that the velocity increases with the increase in $M$ for $\lambda=1.5$. This reverse behaviour in velocity profiles is due to the formation of inverted boundary layer formation for the case of $\lambda>1$. As seen from the Figures 9 and 10 that outer velocity has a significant effect to change the velocity behaviour which helps to improve the quality of the final product in manufacturing processes. 
Journal of Thermal Engineering, Research Article, Vol. 7, No. 4, pp. 823-844, May, 2021

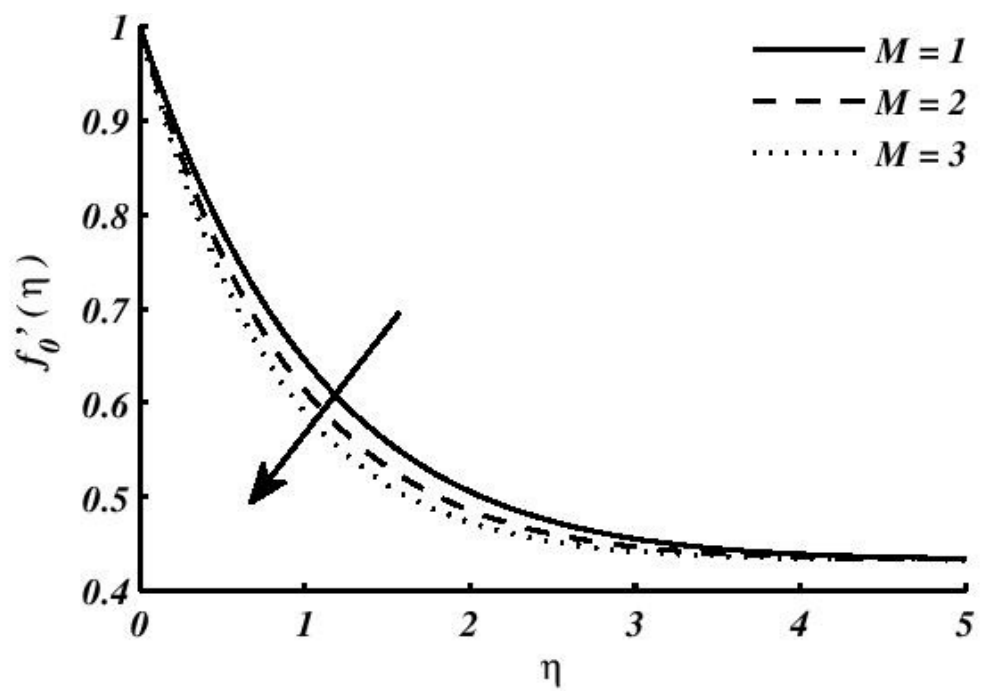

Figure 9. $f_{0}{ }^{\prime}(\eta)$ for distinct $M$, when $\beta=0.5, \mathrm{~S}=1, l=\pi / 2, R=1, \operatorname{Pr}=0.71, \gamma=\pi / 3$ and $\lambda=0.5$

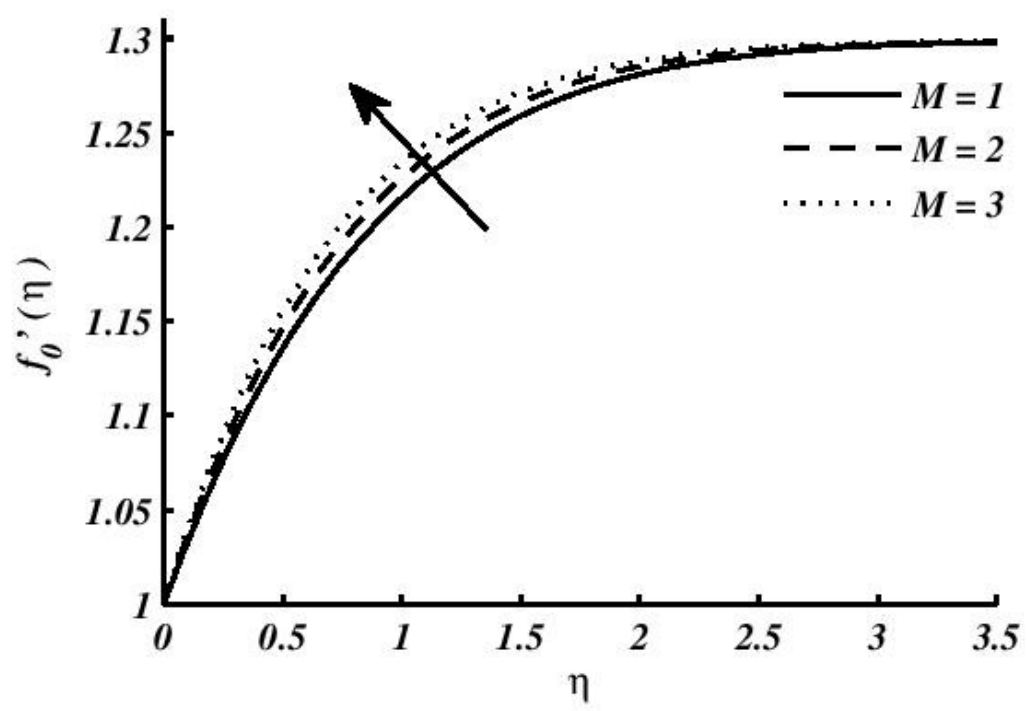

Figure 10. $f_{0}^{\prime(\eta)}$ for distinct $M$, when $\beta=0.5, \mathrm{~S}=1, l=\frac{\pi}{2}, R=1, \operatorname{Pr}=0.71, \gamma=\frac{\pi}{3}$ and $\lambda=1.5$

Table 3. Result of $f_{0}^{\prime \prime}(0)$ and $-\theta^{\prime}(0)$ for different entries of $M$, when $\beta=0.5, S=1, l=\pi / 2, R=1, \operatorname{Pr}=$ 0.71 and $\gamma=\pi / 3$.

\begin{tabular}{|c|c|c|c|c|}
\hline$\lambda$ & $\alpha$ & $M$ & $f_{0}^{\prime \prime}(0)$ & $-\theta^{\prime}(0)$ \\
\hline \multirow{3}{*}{0.5} & 0.55536 & 1 & -0.53459 & -1.20085 \\
& 0.48407 & 2 & -0.62643 & -1.64573 \\
& 0.43444 & 3 & -0.70660 & -2.18123 \\
\hline \multirow{3}{*}{1.5} & & & & \\
& -0.22594 & 1 & 0.34488 & 0.14494 \\
& -0.20710 & 2 & 0.38538 & 0.15071 \\
& -0.19229 & 3 & 0.42210 & 0.15541 \\
\hline
\end{tabular}




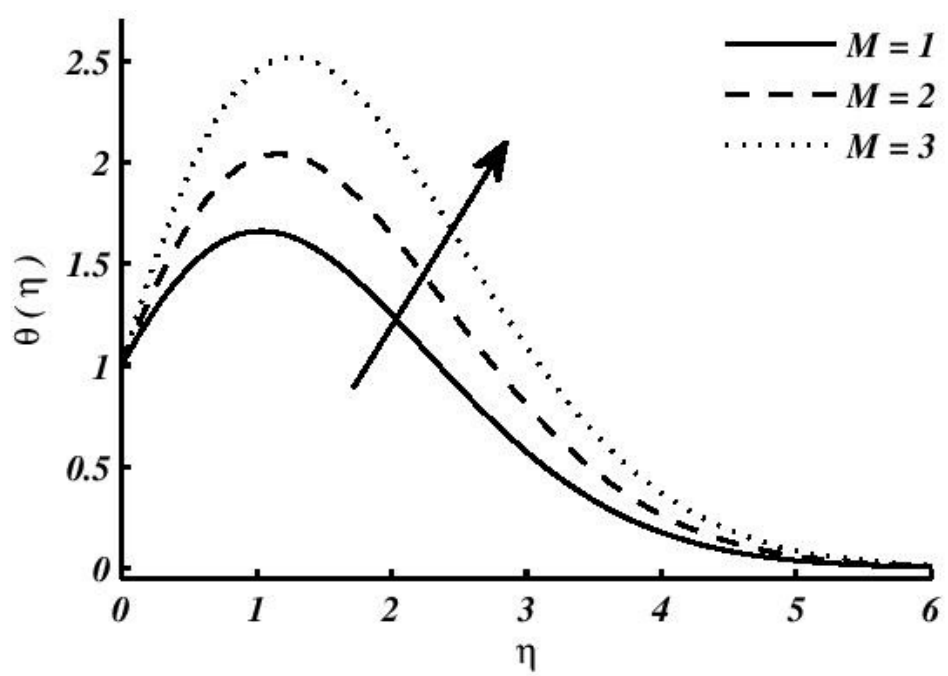

Figure 11. $\theta(\eta)$ for distinct $M$, when $\beta=0.5, S=1, l=\pi / 2, R=1, \operatorname{Pr}=0.71, \gamma=\pi / 3$ and $\lambda=0.5$

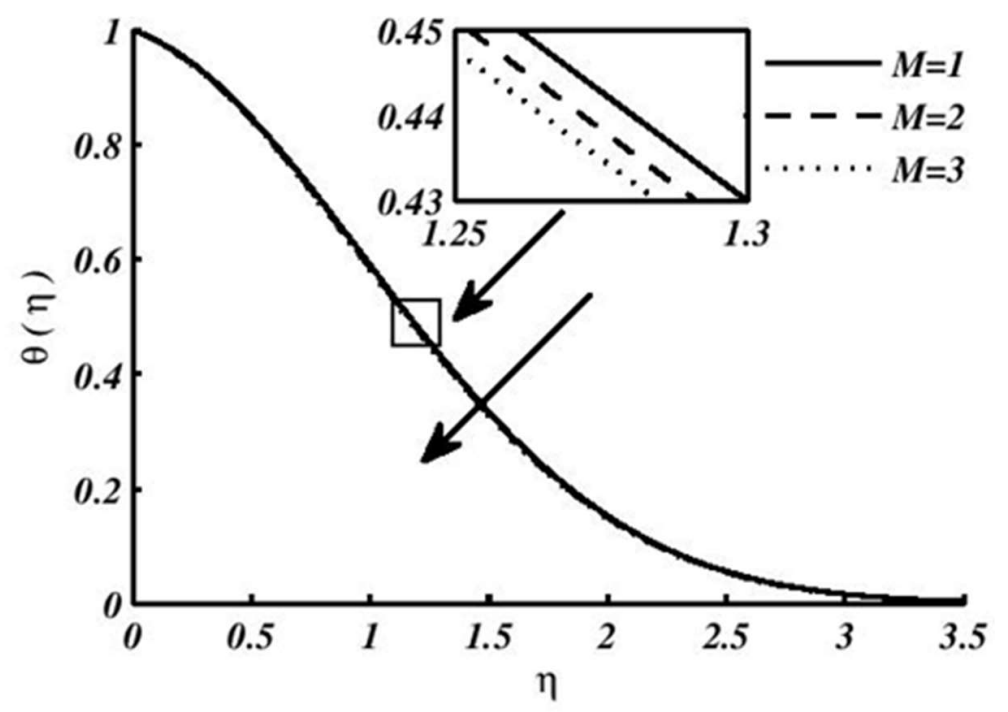

Figure 12. $\theta(\eta)$ for distinct $M$, when $\beta=0.5, \mathrm{~S}=1, l=\frac{\pi}{2}, R=1, \operatorname{Pr}=0.71, \gamma=\frac{\pi}{3}$ and $\lambda=1$

Figures 11 and 12 display the profiles of temperature with variation in the entries of Chandershekhar number $M$ for $\lambda=0.5$ and $\lambda=1.5$ respectively. For $\lambda=0.5$, Figure 11 show that temperature profile increases with increase in the values of magnetic parameter $M$. For $\lambda=1.5$ in Figure 12, a decline in temperature profile is noticed for rise in $M$. Table 3 gives computed values proportional to the $C_{f}$ and $\mathrm{Nu}_{\mathrm{x}}$ for distinct entries of Chandershekhar number $M$ and outer velocity parameter $\lambda$. Other than this, in Figure $12(\lambda=1.5)$ the dispersion in the temperature profile curve for distinct magnitude of $M$ is less as compared to Figure11 $(\lambda=0.5)$. The separation in temperature profile curves less is due to the presence of greater value of outer velocity parameter $\lambda$. Hence, outer velocity parameter $\lambda$ reduces the impact of $M$. Thus, to control the magnetic field in the flow, we use higher value of outer velocity parameter $\lambda$.From Table 3, we observed that with the increase in magnetic parameter $M, C_{f}\left(\propto f_{0}^{\prime \prime}(0)\right)$ andNu $\mathrm{u}_{\mathrm{x}}\left(\propto-\theta^{\prime}(0)\right)$ rise for $\lambda=$ 1.5 and decline for $\lambda=0.5$.

The effect of striking angle parameter $\gamma$ on dimensionless velocity for $\lambda=0.5$ and $\lambda=1.5$ are displayed by images 13 and 14. Here, velocity profile increases with increasing the striking angle parameter $\gamma$. On the other hand,

in Figure 14 for $\lambda>1$, it has been observed that as we increase the striking angle parameter $\lambda$, the velocity profile is inverted. 
Journal of Thermal Engineering, Research Article, Vol. 7, No. 4, pp. 823-844, May, 2021

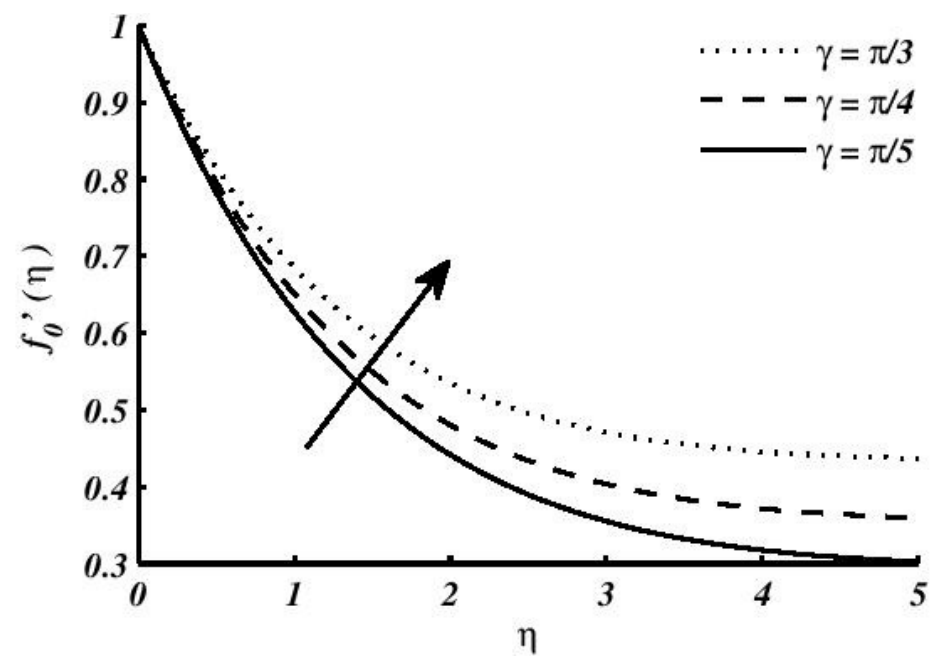

Figure 13. $f_{0}{ }^{\prime}(\eta)$ for distinct $\gamma$, when $M=0.1, \beta=0.5, S=1, l=\pi / 2, R=1, \operatorname{Pr}=0.71$ and $\lambda=0.5$

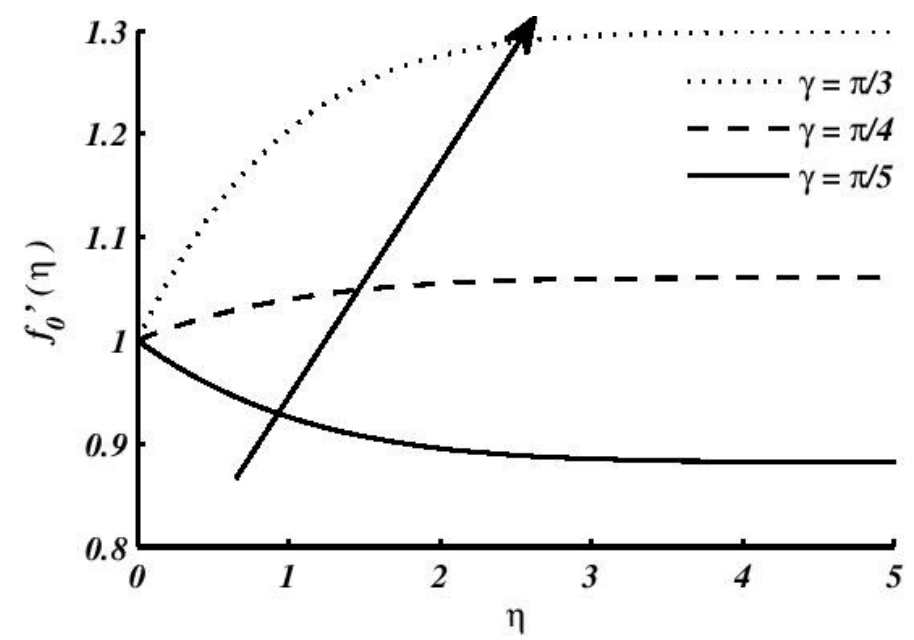

Figure 14. $f_{0}{ }^{\prime}(\eta)$ for distinct $\gamma$, when $M=0.1, \beta=0.5, S=1, l=\pi / 2, R=1, \operatorname{Pr}=0.71$ and $\lambda=1$.

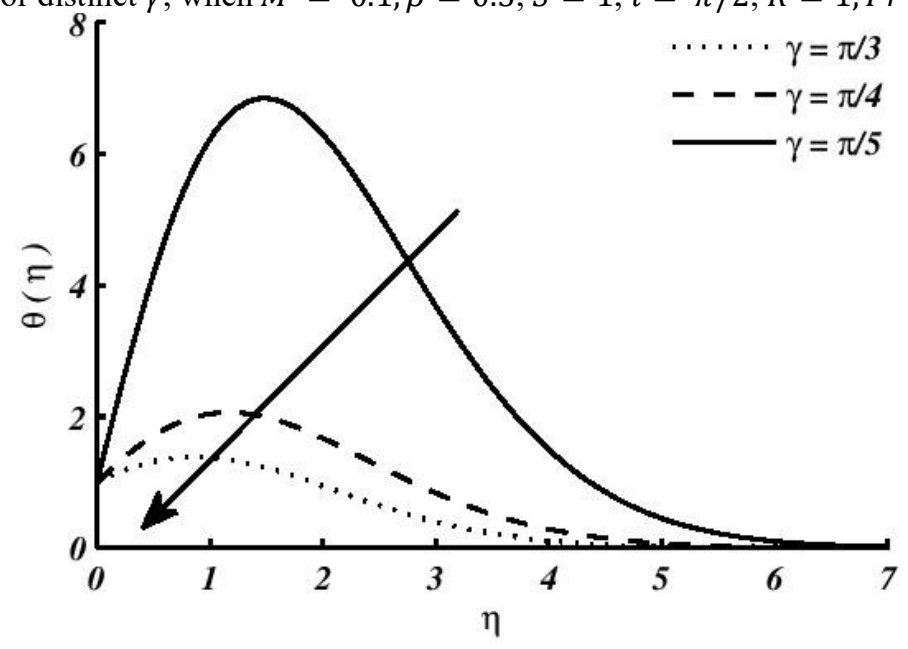

Figure 15. $\theta(\eta)$ for distinct $\gamma$, when $M=0.1, \beta=0.5, S=1, l=\pi / 2, R=1, \operatorname{Pr}=0.71, \gamma=\pi / 3$ and $\lambda=0.5$. 


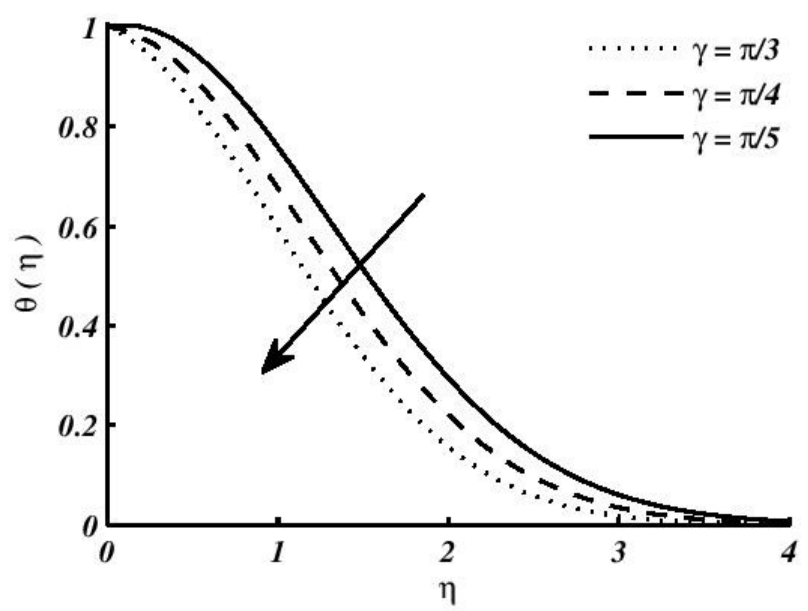

Figure 16. $\theta(\eta)$ for distinct $\gamma$, when $M=0.1, \beta=0.5, S=1, l=\pi / 2, R=1, \operatorname{Pr}=0.71, \gamma=\pi / 3$ and $\lambda=1.5$.

Figures 15 and 16 shows the effect of striking angle parameter $\gamma$ on temperature profile for two different cases of $\lambda$. In both situations, dimensionless temperature profile reduced for large value of striking angle parameter $\gamma$. Also, it has been noticed that in existence of greater outer velocity parameter $\lambda$ (Figure 16), the effect of striking angle parameter $\gamma$ is less with comparison of less outer velocity parameter $\lambda$ (Figure 15). This effect of outer velocity parameter $\lambda$ is observed by the separation of temperature profile curves in Figures 15 and 16. Table 4 shows computed values proportional to $C_{f}$ and $N u_{x}$ for distinct entries of $\gamma$ and $\lambda$. From Table 4 it has been observed that $C_{f}\left(\propto f_{0}^{\prime \prime}(0)\right)$ and $N u_{x}\left(\propto-\theta^{\prime}(0)\right)$ depicts same decreasing trend in both the cases of $\lambda$ as $\gamma$ increases.

Table 4. Results of $f_{0}{ }^{\prime \prime}(0)$ and $-\theta^{\prime}(0)$ for distinct entries of striking angle parameter $\gamma$, when $\beta=0.5, S=1, l=$ $\pi / 2, M=0.1, R=1$ and $\operatorname{Pr}=0.71$.

\begin{tabular}{|c|c|c|c|c|}
\hline$\lambda$ & $\alpha$ & $\gamma$ & $f_{0}^{\prime \prime}(0)$ & $-\theta^{\prime}(0)$ \\
\hline \multirow{3}{*}{0.5} & 0.65525 & $\pi / 3$ & -0.43628 & -0.85297 \\
& 0.78252 & $\pi / 4$ & -0.47996 & -1.67684 \\
& 0.88807 & $\pi / 5$ & -0.59076 & -6.88319 \\
\hline \multirow{3}{*}{1.5} & -0.24818 & $\pi / 3$ & 0.30403 & 0.13842 \\
& -0.05403 & $\pi / 4$ & 0.05794 & 0.03261 \\
& 0.11202 & $\pi / 5$ & -0.10723 & -0.07391 \\
\hline
\end{tabular}

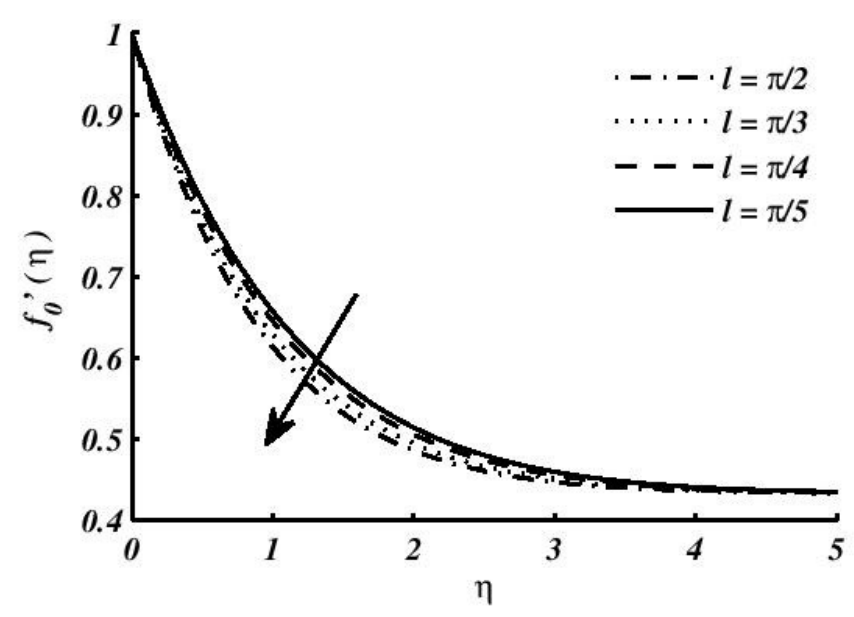

Figure 17. $f_{0}{ }^{\prime}(\eta)$ for distinct $l$, when $M=2, R=1, \beta=0.5, S=1, \gamma=\pi / 3, \operatorname{Pr}=0.71$, and $\lambda=0.5$. 


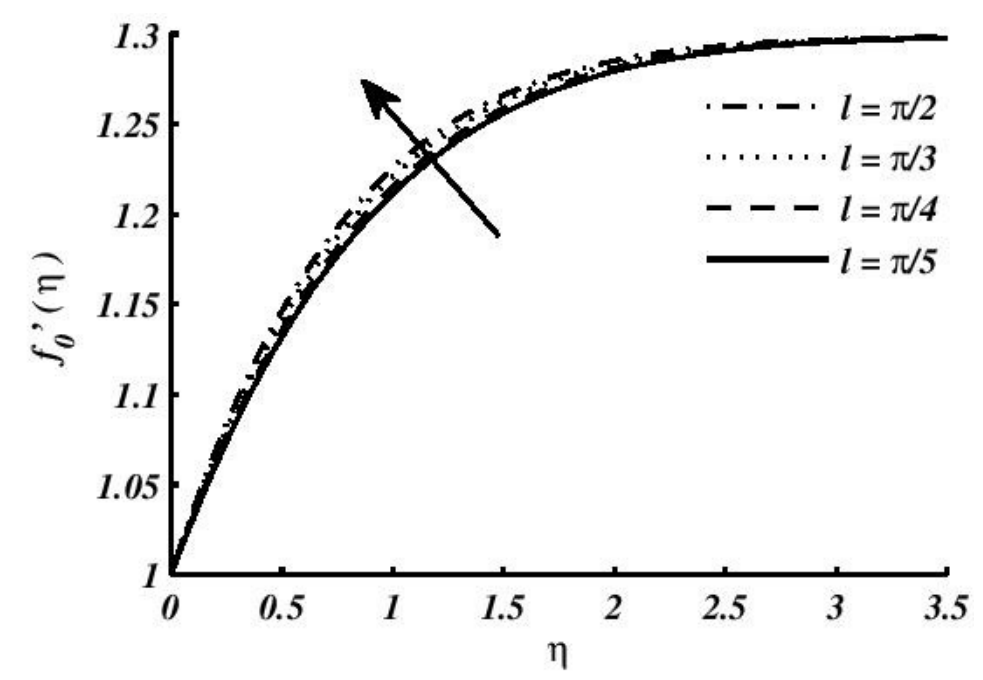

Figure 18. $f_{0}{ }^{\prime}(\eta)$ for distinct $l$, when $M=2, R=1, \beta=0.5, S=1, \gamma=\pi / 3, \operatorname{Pr}=0.71$ and $\lambda=1.5$.

Figures 17 and 18 plotted to analyse the influence of $l$ on dimensionless velocity profiles for $\lambda=0.5$ and $\lambda=$ 1.5 respectively. Here, reduction in velocity profile has been noticed with the increasing value of $l$ for $\lambda<1$ in Figure 17. Reason of this pattern is due to increase in the value of aligned angle that strengthens the applied magnetic field which generate opposite force to flow after increasing magnetic field, known as Lorentz force and as aligned angle increases, resistance goes increases on fluid particle. This force has capacity to reduce velocity profile In Figure 18 an opposite trend of velocity is observed. In both the cases, the momentum boundary layer thickness decreases as we increase in the angle of aligned magnetic field. This opposite trend in velocity profiles and inversion of boundary layer is obtained due to the presence of outer velocity parameter $\lambda$ greater than one.

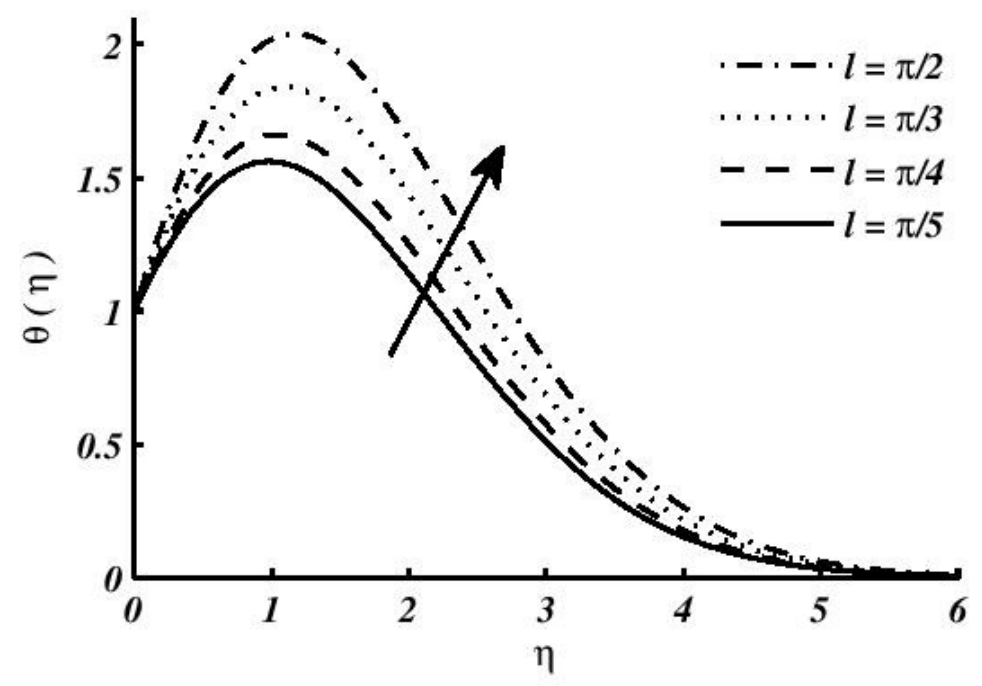

Figure 19. $\theta(\eta)$ for distinct $l$, when $M=2, \beta=0.5, S=1, \gamma=\pi / 3, R=1, \operatorname{Pr}=0.71$ and $\lambda=0.5$.

Figures 19 and 20 described the effect of $l$ on dimensionless temperature profiles for $\lambda=0.5$ and $\lambda=1.5$ respectively. Therefore, temperature of fluid increases with increasing values of $l$ for $\lambda<1$ in Figure 19 whereas fluid temperature decreases for $\lambda>1$ in Figure 20. Computed results of $f_{0}^{\prime \prime}(0)$ and $-\theta^{\prime}(0)$ for distinct entries of $l$ and $\lambda$ have been displayed in Table 5. From Table 5, it is noticed that $C_{f}\left(\propto f_{0}^{\prime \prime}(0)\right)$ and $\mathrm{Nu}_{\mathrm{x}}\left(\propto-\theta^{\prime}(0)\right)$ both increases as aligned angle of magnetic field $l$ decreases for $\lambda<1$ and opposite trend of $C_{f}$ and $\mathrm{Nu}_{\mathrm{x}}$ has been observed for $\lambda>1$. 
Journal of Thermal Engineering, Research Article, Vol. 7, No. 4, pp. 823-844, May, 2021

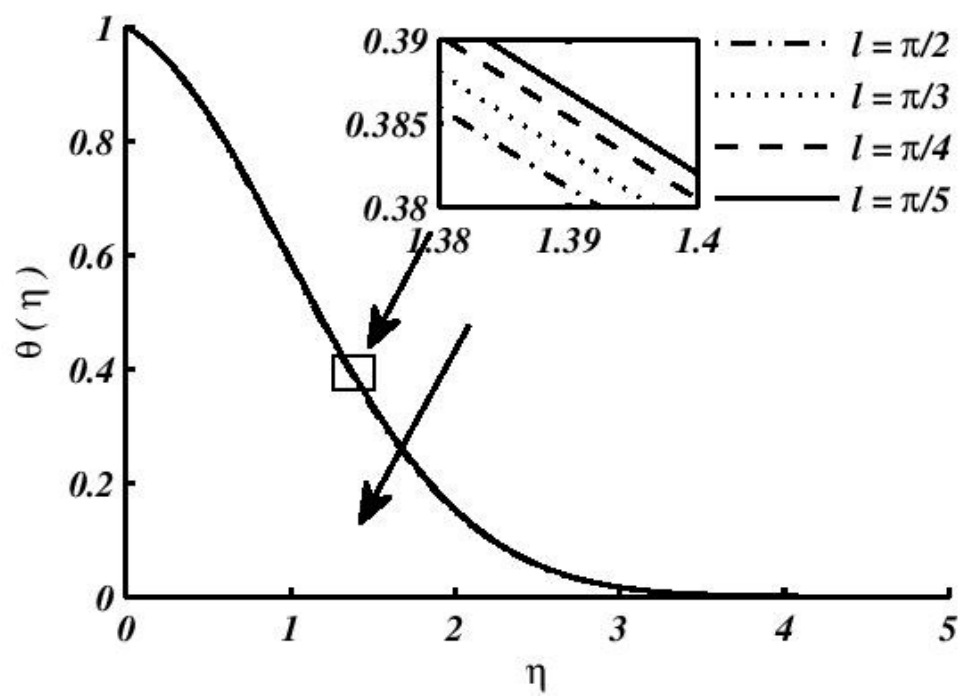

Figure 20. $\theta(\eta)$ for distinct $l$, when $M=2, \beta=0.5, S=1, \gamma=\pi / 3, R=1, \operatorname{Pr}=0.71$ and $\lambda=1.5$.

Table 5. Computed results of $f_{0}{ }^{\prime \prime}(0)$ and $-\theta^{\prime}(0)$ for distinct entries of $l$, when $M=2, \beta=0.5, S=1, \gamma=\pi / 3$, $R=1$ and $\operatorname{Pr}=0.71$.

\begin{tabular}{|c|c|c|c|c|}
\hline$\lambda$ & $\alpha$ & $l$ & $f_{0}^{\prime \prime}(0)$ & $-\theta^{\prime}(0)$ \\
\hline \multirow{3}{*}{0.5} & 0.48407 & $\pi / 2$ & -0.62643 & -1.64573 \\
& 0.67983 & $\pi / 3$ & -0.58229 & -1.41403 \\
& 0.55536 & $\pi / 4$ & -0.53459 & -1.20085 \\
& 0.58448 & $\pi / 5$ & -0.50292 & -1.07685 \\
\hline \multirow{3}{*}{1.5} & -0.20710 & $\pi / 2$ & 0.38538 & 0.15071 \\
& -0.21591 & $\pi / 3$ & 0.36568 & 0.14798 \\
& -0.22594 & $\pi / 4$ & 0.34488 & 0.14494 \\
& -0.23289 & $\pi / 5$ & 0.33140 & 0.14288 \\
\hline
\end{tabular}

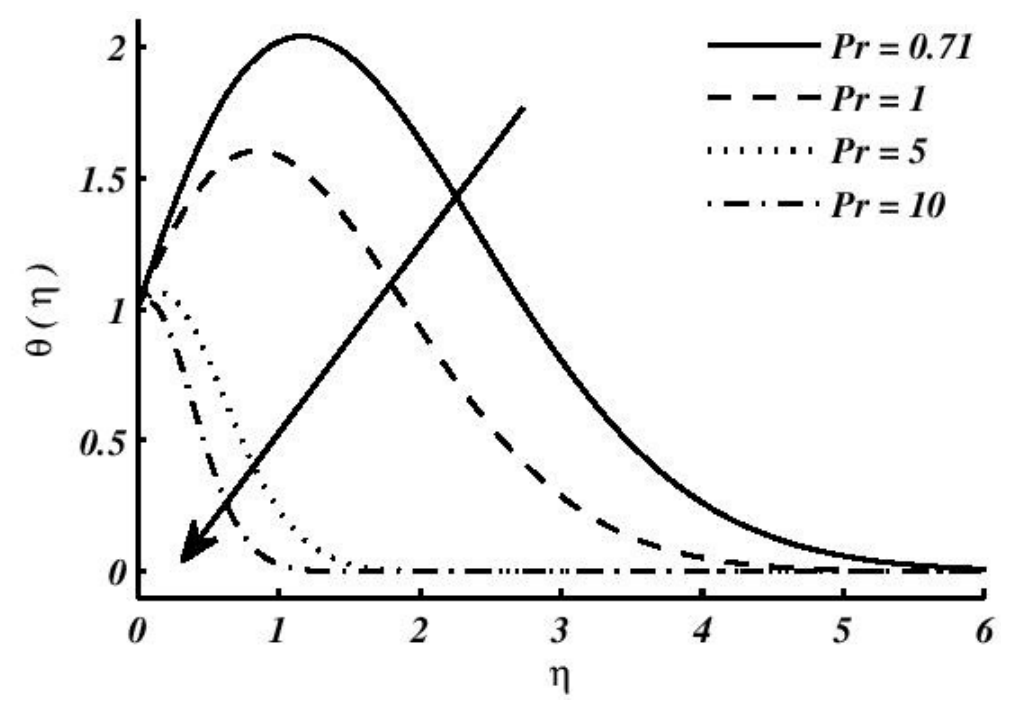

Figure 21. $\theta(\eta)$ for distinct $\operatorname{Pr}$, when $M=2, \beta=0.5, S=1, \gamma=\pi / 3, R=1, l=\pi / 2$ and $\lambda=0.5$. 


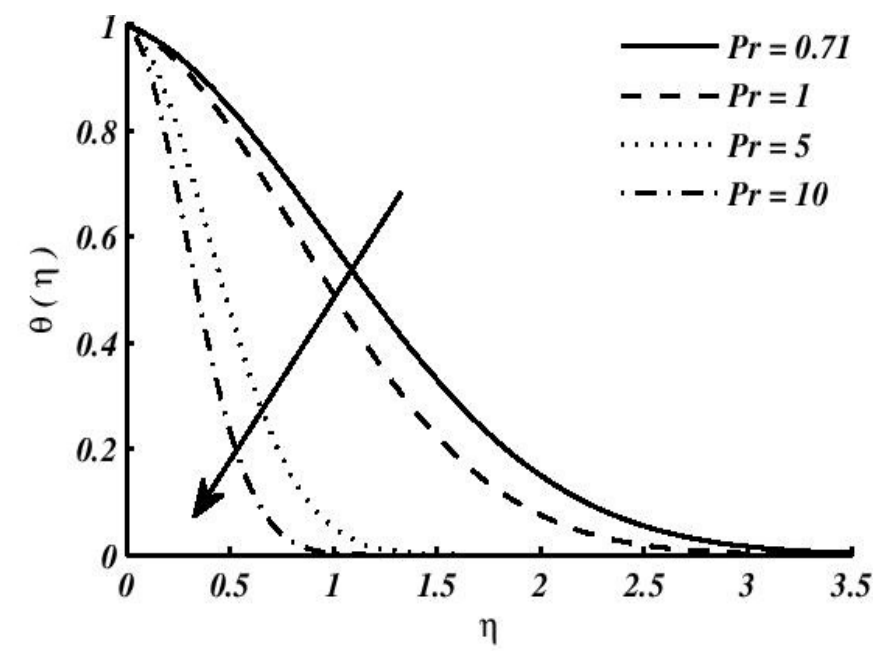

Figure 22. $\theta(\eta)$ for distinct $\operatorname{Pr}$, when $M=2, \beta=0.5, S=1, \gamma=\pi / 3, R=1, l=\pi / 2$ and $\lambda=1$.

The effectiveness of $\operatorname{Pr}$ on temperature has been displayed by Figure 21 and 22 for $\lambda=0.5$ and $\lambda=1.5$ respectively. The decrease in temperature has been observed for large value of $P r$, thereby increasing Prandtl number resulting decrease in thermal diffusion and results in thinning of boundary layer. However, Figure 21displays the fluid temperature in the vicinity of surface increase for a while and decreases thereafter. This happen because stretching velocity exceeds the outer velocity and no slip effect dominates thereat. Figure 22 gives the effect of Prandtl number and fluid temperature when $\lambda=1.5$ Herein, the effects are same as that of $\lambda=0.5$, but temperature gradient is large and no increase of fluid temperature near vicinity of the surface as the outer fluid velocity is greater than stretching sheet velocity.

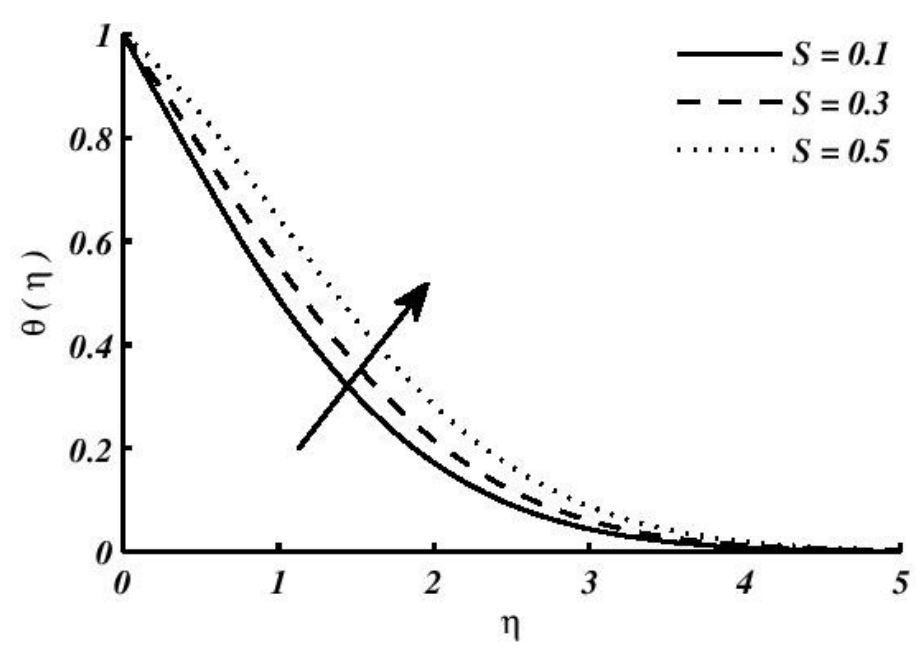

Figure 23. $\theta(\eta)$ for distinct $S$, when $M=2, \beta=0.5, \gamma=\pi / 3, l=\pi / 2, R=1, \operatorname{Pr}=0.71$ and $\lambda=0.5$.

The impact of $S$ on dimensionless temperature has been represented in Figures 23 and 24 for two different entries of $\lambda$. Generally, the internal heat generation/absorption raises the heat transport. The heat generation source leads to a greater thermal diffusion layer that may raise thermal boundary layer thickness. In both situations of $\lambda$, the temperature increases as we rise the heat source parameter $S$. Computed results of $f_{0}^{\prime \prime}(0)$ and $-\theta^{\prime}(0)$ for distinct entries of $S$ and $\lambda$ have been shown in Table 6. From Table 6 , it is noticed that $C_{f}\left(\propto f_{0}^{\prime \prime}(0)\right)$ is not significantly dependent from the heat source parameter $S$ in both the cases of $\lambda$. Also, in both cases of $\lambda, N u_{x}\left(\propto-\theta^{\prime}(0)\right)$ decreases with an increase in heat source parameter $S$ which results a reduction in the rate of heat transfer in fluid. Due to the reduction of rate of heat transfer in fluid, the fluid temperature increases (shown in Figures 23 and 24). 
Journal of Thermal Engineering, Research Article, Vol. 7, No. 4, pp. 823-844, May, 2021

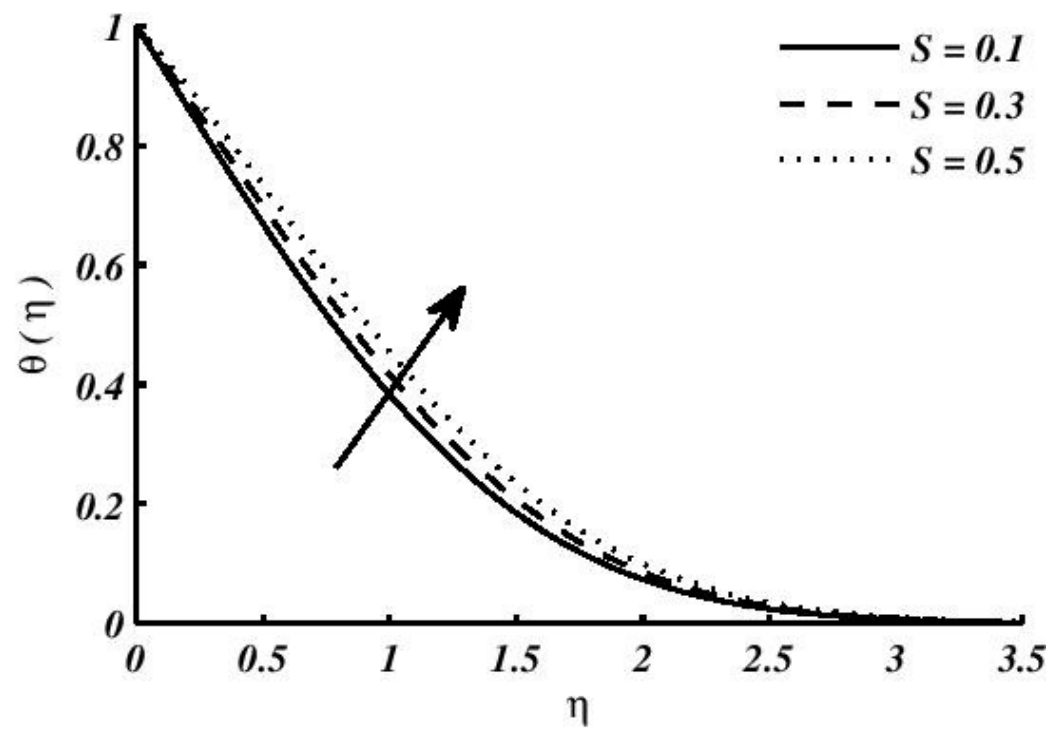

Figure 24. $\theta(\eta)$ for distinct $S$, when $M=2, \beta=0.5, \gamma=\pi / 3, l=\pi / 2, R=1, \operatorname{Pr}=0.71$ and $\lambda=1.5$.

Table 6. Results of $f_{0}{ }^{\prime \prime}(0)$ and $-\theta^{\prime}(0)$ for distinct entries of striking angle parameter $S$, when $M=2, \beta=0.5, \gamma=$ $\pi / 3, l=\pi / 2, R=1$ and $\operatorname{Pr}=0.71$.

\begin{tabular}{|c|c|c|c|c|}
\hline$\lambda$ & $\alpha$ & $S$ & $f_{0}^{\prime \prime}(0)$ & $-\theta^{\prime}(0)$ \\
\hline \multirow{3}{*}{0.5} & 0.48407 & 0.1 & -0.62643 & 0.51142 \\
& 0.48407 & 0.3 & -0.62643 & 0.36880 \\
& 0.48407 & 0.5 & -0.62643 & 0.18167 \\
\hline \multirow{3}{*}{1.5} & -0.20710 & 0.1 & 0.38538 & 0.67323 \\
& -0.20710 & 0.3 & 0.38538 & 0.57957 \\
& -0.20710 & 0.5 & 0.38538 & 0.47600 \\
\hline
\end{tabular}

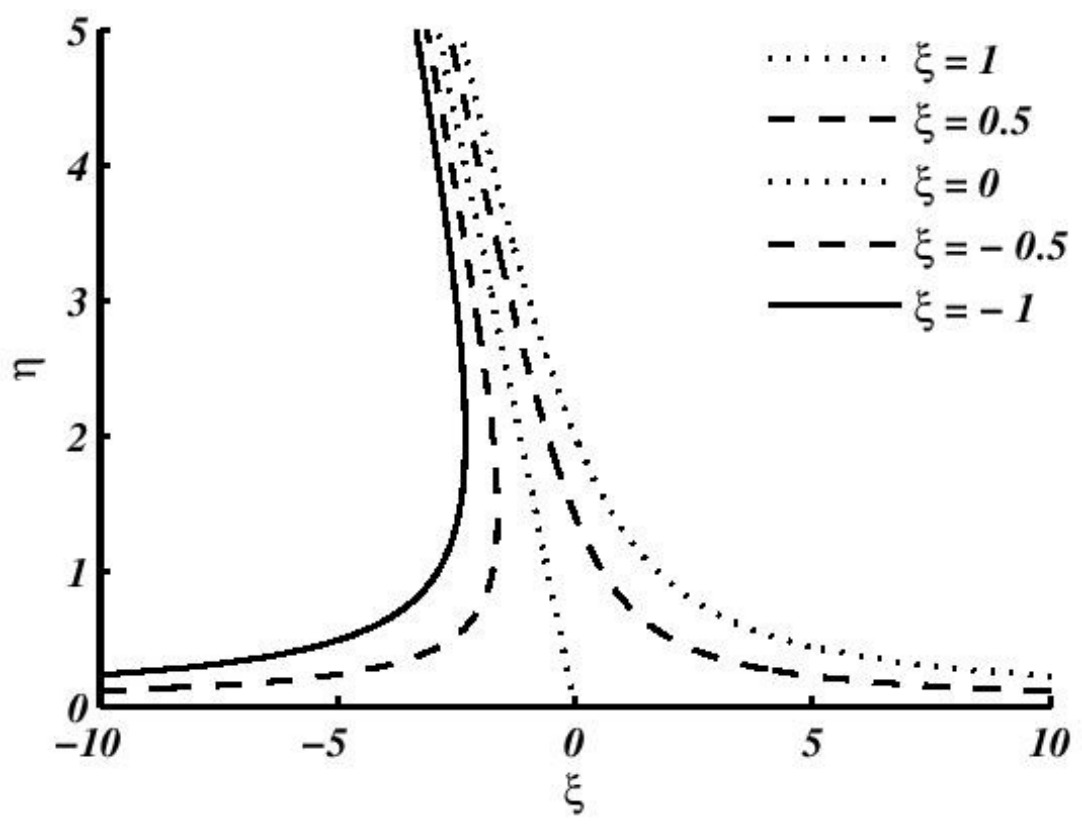

Figure 25. Streamlines for $\gamma=\pi / 3$ when $\lambda=0.5$ 


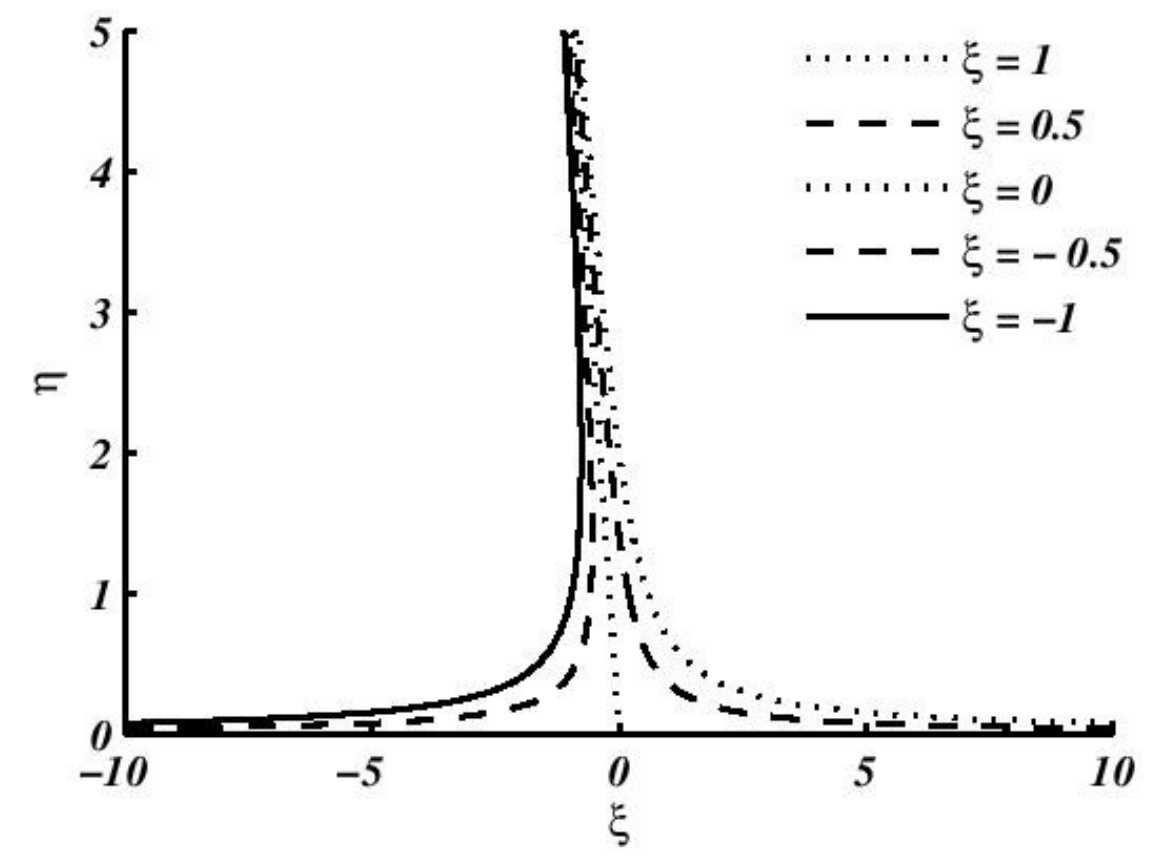

Figure 26. Streamlines for $\gamma=\pi / 3$ when $\lambda=1.5$

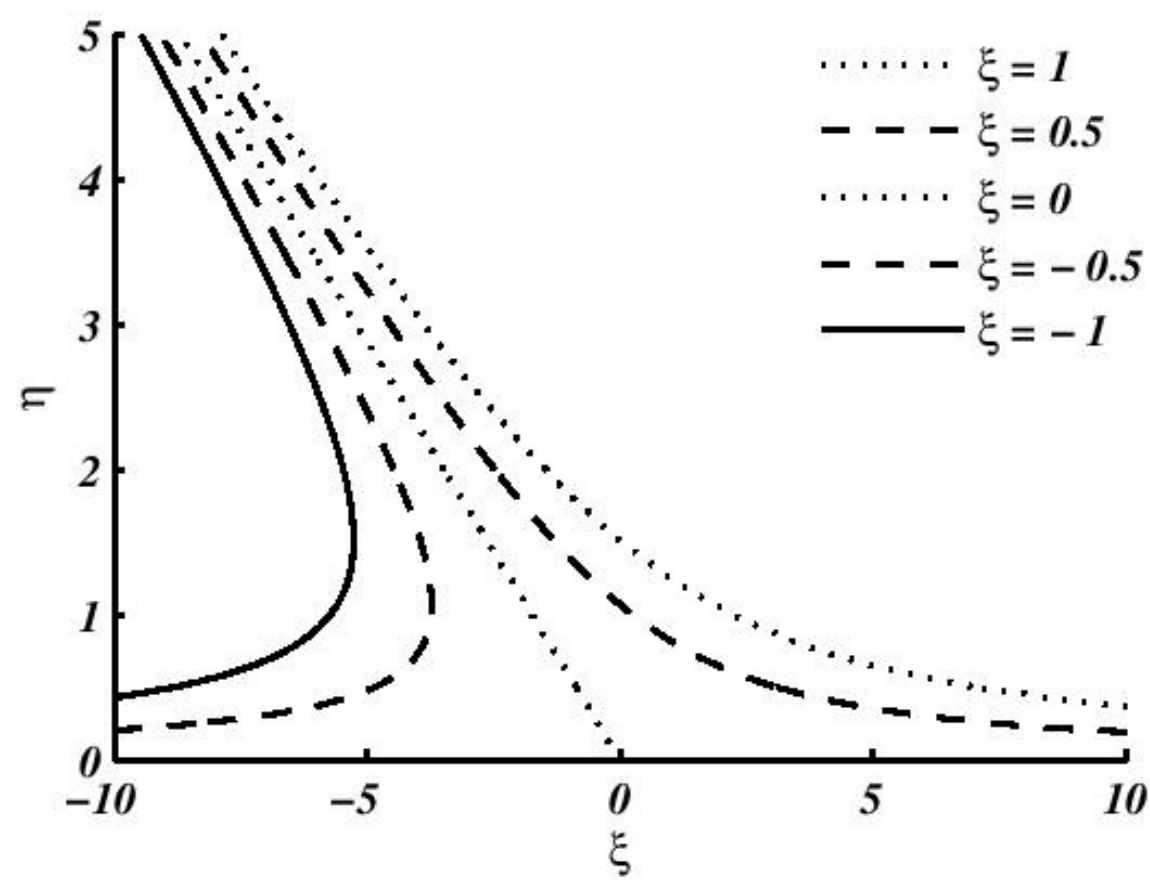

Figure 27. Streamlines for $\gamma=\pi / 6$ when $\lambda=0.5$

Streamlines pattern for $\gamma=\pi / 3$ has been represented by Figures 25 and 26 for $\lambda<1$ and $\lambda>1$ respectively. Also, for $\gamma=\pi / 6$, Figures 27 and 28 demonstrates the streamline for two cases of $\lambda=0.5$ and $\lambda=1.5$. It is clear from the Figures 26 and 28 that the outer velocity has a significant effect on streamlines as the separation gap between the streamlines is less as compared to the Figures 25 and 27. 


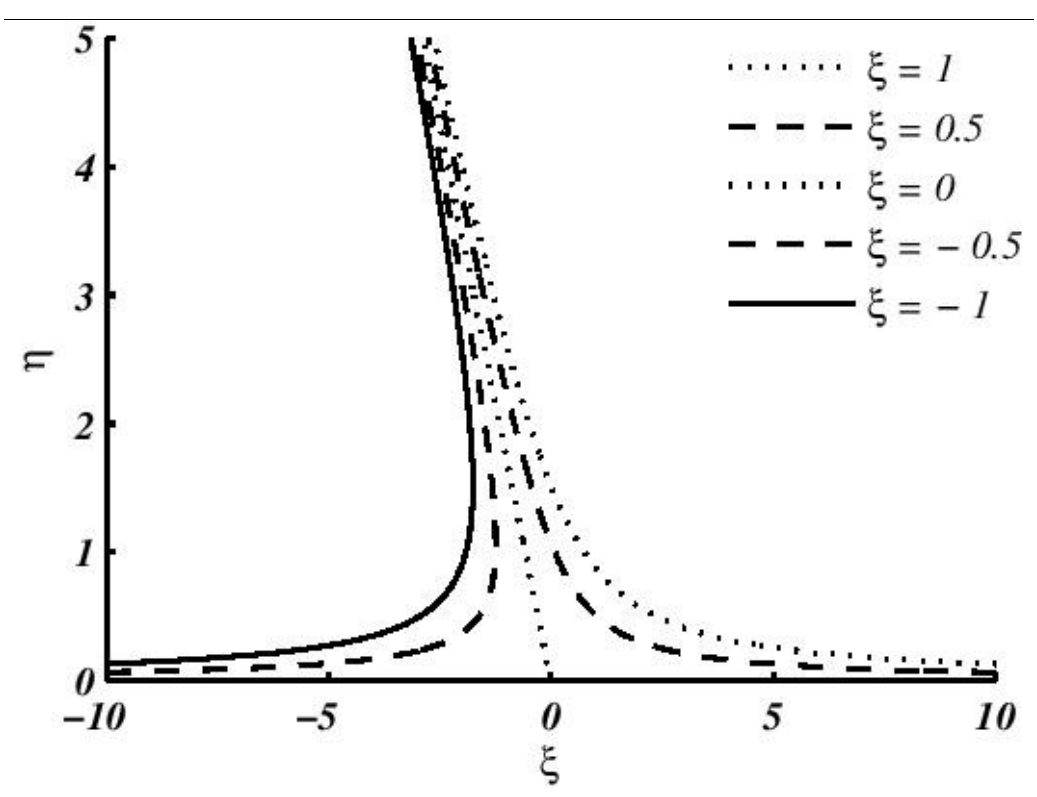

Figure 28. Streamlines for $\gamma=\pi / 6$ when $\lambda=1.5$

\section{CONCLUSIONS}

Steady 2D Casson fluid flow of a non-compressible, viscous, non-orthogonally electrical conducting fluid on a stretching sheet with orthogonal and inclined outer velocity flow has been studied. Runge-Kutta Fehlberg has been used to solve numerically the differential equations with their corresponding boundary conditions through shooting technique. The numerical results obtained in this study include the influence of aligned magnetic field and inclined outer velocity along with heat source and Casson parameter on temperature and velocity profiles of the flow. This analysis revealed major recommendations of the outcomes are compiled as below:

- Fluid velocity and momentum boundary layer thickness decreases with an increase in Casson parameter $\beta$, magnetic parameter $M$ and aligned angle parameterl while fluid velocity increases with an increase in impinging angle parameter $\gamma$ for outer velocity less than one. Apart from this for outer velocity greater than one, the fluid velocity increases with an increase in Casson parameter $\beta$, impinging angle parameter $\gamma$, magnetic parameter $M$ and aligned angle parameter $l$.

- Fluid temperature and thermal boundary layer thickness increases as we increase in Casson parameter $\beta$, magnetic parameter $M$ and aligned angle parameter $l$ whereas reduction in temperature is noticed as impinging angle parameter $\gamma$ increases for outer velocity less than one. Also, for outer velocity greater than one the fluid temperature decreases for increase in Casson parameter $\beta$, impinging angle parameter $\gamma$, magnetic parameter $M$ and aligned angle parameter $l$.

- Increase in Prandtl number $\operatorname{Pr}$ yields decrease in temperature while increase in heat source parameter $S$ results increase in temperature for both the cases of outer velocity parameter $\lambda$.

- In Case of outer velocity greater than one, inverted boundary layer pattern for velocity profiles observed while in case of temperature profiles there is a reduction of separation gap between profiles has been observed which happened due to increase in outer velocity.

These results have possible technological applications in liquid-based systems involving stretching materials. The finding of this study may serve as to control the rate of heat transportation and fluid velocity in many manufacturing processes and industrial applications to make the desired quality of final product. A future study of this analysis can be done by considering stretching cylindrical surfaces. 


\section{NOMENCLATURE}

$l$

$R, b, n, m, k \& \alpha$

$\mathrm{x}, \mathrm{y}$

$T$

$Q$

$q_{w}$

$N u_{x}$

$M$

MHD

$B_{0}$

$f_{0}$

$\mathrm{P}$

$\operatorname{Pr}$

$C_{P}$

$C_{f}$

$\mathrm{K}$

$g_{0} \& h_{0}$

$T_{w}$

$T_{\infty}$

$u, v$

Greek symbols

$\beta$

$\sigma$

$\rho$

$\gamma$

$v$

$\lambda$

$\psi$

$\tau_{w}$

$\theta$

Subscripts

$f$

w

$p$

\author{
Aligned angle parameter \\ Constant \\ Cartesian coordinates \\ Fluid temperature, $\mathrm{T}$ \\ Heat generation, $\mathrm{W}$ \\ Rate of heat transfer, $\mathrm{Wm}^{-2}$ \\ Local Nusselt number \\ Magnetic parameter \\ Magneto hydrodynamic \\ Magnetic field strength, T \\ Normal component of flow \\ Pressure \\ Prandtl number \\ Specific heat at constant pressure, $\mathrm{J} \mathrm{Kg}^{-1} \mathrm{~K}^{-1}$ \\ Skin friction coefficient \\ Thermal conductivity, $\mathrm{W} \mathrm{m}^{-1} \mathrm{~K}^{-1}$ \\ Tangential component of flow \\ Temperature at surface, $\mathrm{K}$ \\ Uniform ambient temperature, $\mathrm{K}$ \\ Velocity component along $\mathrm{x}$ and $\mathrm{y}$ axis, $\mathrm{ms}^{-1}$
}

Casson parameter

Electrical conductivity, $\mathrm{W} \mathrm{m}^{-2} \mathrm{~K}^{-4}$

Fluid density, $\mathrm{Kg} \mathrm{m}^{-3}$

Impinging/striking angle

Kinematic viscosity, $\mathrm{ms}^{-2}$

Outer velocity parameter

Stream function

Wall shear stress, $\mathrm{Pa}$

Dimensionless temperature profile

Refers to fluid

Refers to wall

Refers to pressure

\section{REFERENCES}

[1] Crane LJ. Flow past a stretching plate. Journal of Applied Mathematics and Physics (ZAMP) 1970; 21: 645647.

[2] Andersson HI. MHD flow of a viscoelastic fluid past a stretching surface. ActaMechanica 1992; 95: 227-230.

[3] Cortell R. A note on magnetohydrodynamic flow of a power-law fluid over a stretching sheet. Applied Mathematics and Computation 2005; 168: 557-566. doi:10.1016/j.amc.2004.09.046

[4] Poply V, Singh P, Chaudhary KK. Analysis of laminar boundary layer flow along a stretching cylinder in the presence of thermal radiation. WSEAS Transactions on Fluid Mechanics 2013; 4: 159-164.

[5] Ishak A, Jafar K, Nazar R, Pop I. MHD stagnation point flow towards a stretching sheet. Physica A: Statistical Mechanics and its Applications 2009; 388: 3377-3383.

[6] Singh P, Tomer NS, Kumar A, Sinha D. MHD oblique stagnation-point flow towards a stretching sheet with heat transfer. International Journal of Applied Mathematics and Mechanics 2010; 6: 94-111. 
Journal of Thermal Engineering, Research Article, Vol. 7, No. 4, pp. 823-844, May, 2021

[7] Singh P, Jangid A, Tomer NS, Sinha D. Effects of thermal radiation and magnetic field on unsteady stretching permeable sheet in presence of free stream velocity. International Journal of Physical and Mathematical Sciences 2010; 4: 160-166. doi: 10.5281/zenodo.1081565.

[8] Singh P, Kumar A, Tomer NS, Sinha D. Analysis of porosity effects on unsteady stretching permeable sheet. Walailak Journal of Science and Technology (WJST) 2013; 11: 611-620.

[9] Poply V, Singh P, Yadav AK. A study of temperature-dependent fluid properties on mhd free stream flow and heat transfer over a non-linearly stretching sheet. Procedia Engineering 2015; 127: 391-397. doi:10.1016/j.proeng.2015.11.386.

[10] Poply V, Singh P, Yadav AK. Stability analysis of MHD outer velocity flow on a stretching cylinder. Alexandria Engineering Journal 2017; 57: 2077-2083. doi:10.1016/j.aej.2017.05.025.

[11] Hayat T, Qasim M, Shehzad SA, Alsaedi A. Unsteady stagnation point flow of second grade fluid with variable free stream. Alexandria Engineering Journal 2014; 53: 455-461. doi: 10.1016/j.aej.2014.02.004

[12] Siddheshwar PG, Meenakshi, N. Effects of suction and freestream velocity on a hydromagnetic stagnationpoint flow and heat transport in a Newtonian fluid toward a stretching sheet. Journal of Heat Transfer 2016; 138: 1-4. doi.10.1115/1.4033460.

[13] Mukhopadhyay S, Layek GC. Effects of variable fluid viscosity on flow past a heated stretchingsheet embedded in a porous medium in presence of heat source/sink.Meccanica 2012; 47: 863-876. doi: 10.1007/s11012-011-9457-6.

[14] Singh P, Tomer NS, Sandeep K, Deepa S. Effect of radiation and porosity parameter on magnetohydrodynamic flow due to stretching sheet in porous media. Thermal Science 2011; 15: 517-526. doi:10.2298/TSCI1102517S.

[15] Seddeek MA. Heat and mass transfer on a stretching sheet with a magnetic field in a viscoelastic fluid flow through a porous medium with heat source or sink. Computational Materials Science 2007; 38: 781-787. doi:10.1016/j.commatsci.2006.05.015

[16] Ahmad K, Halim SA, Hanouf Z. Variable viscosity of casson fluid flow over a stretching sheet in porous media with newtonian heating. Journal of Informatics and Mathematical Sciences 2018; 10: 359-370.

[17] Mustafa M, Hayat T, Pop I, Hendi A. Stagnation-point flow and heat transfer of a casson fluid towards a stretching sheet. Zeitschrift für Naturforschung A 2012; 67: 70-76.doi: 10.5560/ZNA.2011-0057.

[18] Kameswaran PK, Shaw S, Sibanda P. Dual solutions of Casson fluid flow over a stretching or shrinking sheet, Sadhana 2014; 39: 1573-1583.

[19] Bhattacharyya K, Hayat T, Alsaedi A. Exact solution for boundary layer flow of Casson fluid over a permeable stretching/shrinking sheet. ZAMM - J. Appl. Math. Mech. Z. FürAngew. Math. Mech 2014; 94: 522-528. doi: 10.1002/zamm.201200031

[20] Megahed AM. Effect of slip velocity on Casson thin film flow and heat transfer due to unsteady stretching sheet in presence of variable heat flux and viscous dissipation. Appl. Math. Mech. 2015; 36: 1273-1284.

[21] Bhattacharyya K. MHD Stagnation-Point Flow of Casson Fluid and Heat Transfer over a Stretching Sheet with Thermal Radiation.Journal of Thermodynamics2013; 2013: 1-9. doi.10.1155/2013/169674.

[22] Yaragani HK, Reddy GVR, Makinde OD. Chemical reaction effect on mhd flow of casson fluid with porous stretching sheet. Defect and Diffusion Forum 2018; 389: 100-109.

[23] Mabood F, Das K. Outlining the impact of melting on MHD Casson fluid flow past a stretching sheet in a porous medium with radiation. Heliyon 2019; 5. doi.10.1016/j.heliyon.2019.e01216.

[24] Raza J. Thermal radiation and slip effects on magneto hydrodynamic (MHD) stagnation point flow of Casson fluid over a convective stretching sheet. Propulsion Power Research 2019; 8: 138-146.

[25][25] Prabhakar B, Bandari S, Kumar CK. Effects of inclined magnetic field and chemical reaction on flow of a casson nanofluid with second order velocity slip and thermal slip over an exponentially stretching sheet. International Journal of Applied and Computational Mathematics 2017; 3: 2967-2985.

[26] Jusoh R, Nazar R. Effect of heat generation on mixed convection of micropolar Casson fluid over a stretching/shrinking sheet with suction. Journal of Physics: Conference Series 2019; 1212: 1-6. doi:10.1088/1742-6596/1212/1/012024. 
Journal of Thermal Engineering, Research Article, Vol. 7, No. 4, pp. 823-844, May, 2021

[27] Megahed AM. MHD viscous Casson fluid flow and heat transfer with second-order slip velocity and thermal slip over a permeable stretching sheet in the presence of internal heat generation/absorption and thermal radiation. The European Physical Journal Plus 2015; 130: 1-17. doi: 10.1140/epjp/i2015-15081-9.

[28] Mahapatra TR, Dholey S, Gupta AS. Heat transfer in oblique stagnation-point flow of an incompressible viscous fluid towards a stretching surface. Heat and Mass Transfer 2007; 43: 767-773. doi: 10.1007/s00231006-0116-8.

[29] Lok YY, Amin N, Pop I. Non-orthogonal stagnation point flow towards a stretching sheet. International Journal of Non-Linear Mechanics 2006; 41: 622-627. doi:10.1016/j.jnonlinmec.2006.03.002

[30] Labropulu F, Li D, Pop I. Non-orthogonal stagnation-point flow towards a stretching surface in a nonNewtonian fluid with heat transfer. International Journal of Thermal Sciences 2010; 49: 1042-1050. doi: 10.1016/j.jijthermalsci.2009.12.005.

[31] Singh P, Sinha D, Tomer NS. Oblique stagnation-point darcy flow towards a stretching sheet. Journal of Applied Fluid Mechanics 2012; 5: 29-37.

[32] Lok YY, Pop I, Ingham DB, Amin N. Mixed convection flow of a micropolar fluid near a non-orthogonal stagnation-point on a stretching vertical sheet. International Journal of Numerical Methods for Heat \& Fluid Flow2009; 19: 459-483. doi:10.1108/09615530910938380.

[33] Lok YY, Merkin JH, Pop I. MHD oblique stagnation-point flow towards a stretching/shrinking surface. Meccanica 2015; 50: 2949-2961. doi: 10.1007/s11012-015-0188-y.

[34] Sheikholeslami M. Influence of magnetic field on $\mathrm{Al}_{2} \mathrm{O}_{3}-\mathrm{H}_{2} \mathrm{O}$ nanofluid forcedconvection heat transfer in a porous lid driven cavity with hot sphere obstacle by means of LBM. Journal of Molecular Liquids 2018; 263: 472-488. doi:10.1016/j.molliq.2018.04.111.

[35] Sheikholeslami M. Solidification of NEPCM under the effect of magnetic field in aporous thermal energy storage enclosure using $\mathrm{CuO}$ nanoparticles. Journal of Molecular Liquids 2018; 263: 303-315. doi: 10.1016/j.molliq.2018.04.144.

[36] Sheikholeslami M, Zeeshan A. Analysis of flow and heat transfer in water basednanofluid due to magnetic field in a porous enclosure with constant heat flux using CVFEM. Computer Methods in Applied Mechanics and Engineering 2017; 320: 68-81.

[37] Asirvatham LG. Nanofluid heat transfer and applications. Journal of Thermal Engineering 2015; 1: 113-115. doi: $10.18186 /$ jte. 93344 .

[38] Sulochana C, Sandeep N, Sugunamma V, Kumar BR. Aligned magnetic field and cross-diffusion effects of a nanofluid over an exponentially stretching surface in porous medium. Applied Nanoscience 2016; 6: $737-$ 746.

[39] Devi R, Poply V, Manimala. Impact of inclined outer velocity in MHD Casson fluid over stretching sheet. International Journal of Advanced Trends in Computer Applications 2019; 1: 32-38.

[40] Vinita V, Poply V. Impact of outer velocity MHD slip flow and heat transfer of nanofluid past a stretching cylinder. Materials Today Proceedings 2019; 26: 3429-3435. doi: 10.1016/j.matpr.2019.11.304.

[41] Mahabaleshwar US, Vinay Kumar PN, Sheremet M. Magneto hydrodynamics flow of a nanofluid driven by a stretching/shrinking sheet with suction. SpringerPlus 2016; 5: 1-9. doi: 10.1186/s40064-016-3588-0.

[42] Gireesha BJ, Ramesh GK, Bagewadi CS. Heat transfer in MHD flow of a dusty fluid over a stretching sheet with viscous dissipation. Advances in Applied Science Research 2012; 3: 2392-2401.

[43] Abel MS, Mahesha N. Heat transfer in MHD viscoelastic fluid flow over a stretching sheet with variable thermal conductivity, non-uniform heat source and radiation. Applied Mathematical Modelling 2008; 32: 1965-1983. doi:10.1016/j.apm.2007.06.038. 